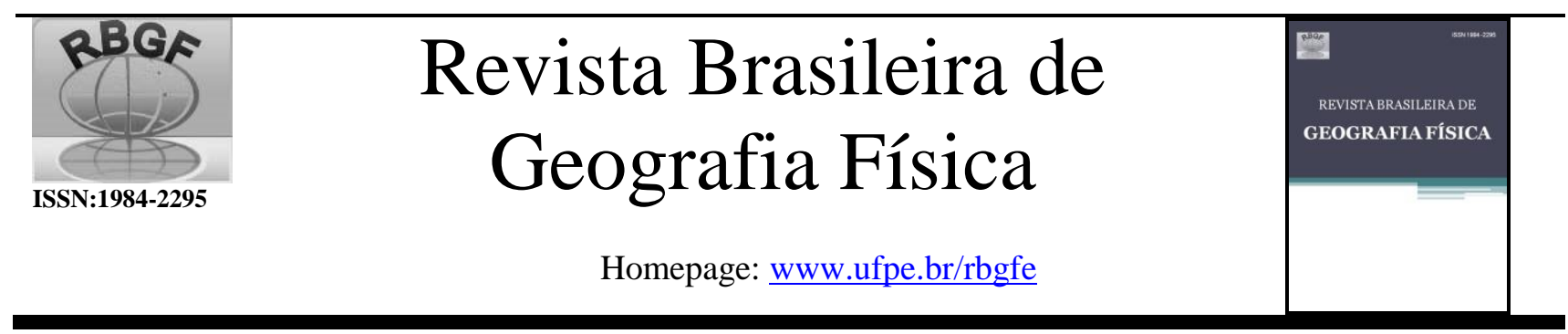

\title{
Dinâmica fluvial na bacia hidrográfica do rio Carapá, inserida na bacia do rio Amazonas
}

\author{
Rinaldo Marques Padilha ${ }^{1}$, Célia Alves de Souza ${ }^{2}$ \\ ${ }^{1}$ Mestrado em Geografia pela Universidade do Estado de Mato Grosso - UNEMAT. Autor Correspondente: rinaldomarques@ @otmail.com. \\ ${ }^{2}$ Professora do Programa de Pós-graduação em Geografia (PPGEO) da Universidade do Estado de Mato Grosso/Laboratório de Pesquisa e Estudo em \\ Geomorfologia Fluvial. UNEMAT. celiaalvesgeo@globo.com.
}

Artigo recebido em 09/11/2017 e aceito em 24/07/2018

\begin{abstract}
R E S U M O
O estudo teve como objetivo analisar a dinâmica fluvial na bacia hidrográfica do rio Carapá, em Colíder e Nova Canaã do Norte - MT. Para o monitoramento da dinâmica fluvial, foram realizadas coletas e análises de sedimentos de fundo, margem e suspensão, instalação de pinos, estacas e aferição de batimetria. A bacia do Carapá é de sexta ordem, o rio principal possui 163,526 km de extensão. A dinâmica fluvial revelou que o rio não tem um padrão regular, podendo ser encontrados trechos sinuosos, meandrantes e retilíneos. A área molhada da seção variou entre $0,248 \mathrm{~m}^{2}$ ( $\mathrm{seção} 1$ período de estiagem) e 103,350 $\mathrm{m}^{2}$ (seção 11 - período chuvoso). A velocidade do fluxo foi maior no período chuvoso em todas as seções e a maior vazão variou entre 2,174 m³ $/ \mathrm{s}$ na seção 1 e $75,297 \mathrm{~m}^{3} / \mathrm{s}$ na seção 11 no período chuvoso. Nos sedimentos de fundo, predominaram os grosseiros na maioria das seções nos dois períodos. A fração silte predominou nos sedimentos de margem na maioria das seções. A magnitude da erosão medida por pinos variou entre $0,07 \mathrm{~cm} / \mathrm{mês}$ (seção 1) e $1,04 \mathrm{~cm} /$ mês (seção 11). As seções 1,3 e 10 os agregados são estáveis em água, concentrando a maior parte das partículas entre 1 a $4 \mathrm{~mm}$, enquanto as demais seções se mostraram mais susceptíveis a erosão. A concentração de sedimentos em suspensão variou entre $12 \mathrm{mg} / \mathrm{L}$ e $252 \mathrm{mg} / \mathrm{L}$ ao longo do canal. A descarga sólida em suspensão registrada ficou entre $0,135 \mathrm{t} / \mathrm{d}$ (seção 1 , período seco) e 396,850 t/d (seção 11, período chuvoso).

Palavras chave: Colíder, sedimento, agregado, erosão, vazão.
\end{abstract}

\section{River dynamics in the Carapá river hydrographic basin, inserted in the Amazon river basin.}

\section{A B S T R A C T}

The objective of this study was to analyze river dynamics in the Carapá river hydrographic basin, in Colíder and Nova Canaã do Norte - MT. In order to monitor the river dynamics, collections and analyzes of the bottom sediments, margin and suspension, installation of pins, stakes and bathymetry measurement were accomplished. The Carapá basin is of the sixth order, the main river is $163.526 \mathrm{~km}$ long. The river dynamics revealed that the river does not have a regular pattern, and sinuous, meandering and rectilinear stretches can be found. The wet area of the section varied between $0.248 \mathrm{~m}^{2}$ (section 1 - dry season) and $103.350 \mathrm{~m}^{2}$ (section 11 - rainy season). The flow velocity was higher in the rainy season in all sections and the highest flow ranged between $2,174 \mathrm{~m}^{3} / \mathrm{s}$ in section 1 and 75,297 $\mathrm{m}^{3} / \mathrm{s}$ in section 11 in the rainy season. In the bottom sediments, the thicker ones were predominant in the most sections in the two periods. The silt fraction predominated in the margin sediments in the most sections. The magnitude of the erosion measured by pins ranged from $0.07 \mathrm{~cm} /$ month (section 1) to $1.04 \mathrm{~cm} /$ month (section 11). In the sections 1,3 and 10, the aggregates are stable in water, concentrating the most of the particles between 1 and $4 \mathrm{~mm}$, while the other sections are more susceptible to erosion. The concentration of the suspended sediments ranged from $12 \mathrm{mg} / \mathrm{L}$ to $252 \mathrm{mg} / \mathrm{L}$ along the canal. The registered solid discharge in suspension was between $0.135 \mathrm{t} / \mathrm{d}$ (section 1 , dry season) and $396,850 \mathrm{t} / \mathrm{d}$ (section 11, rainy season).

Key words: Colíder, sediment, aggregate, erosion, flow.

\section{Introdução}

O estudo foi realizado na bacia hidrográfica do Carapá que está inserida na bacia hidrográfica do Teles e em macro escala compõem a bacia
Amazônica. O estudo da dinâmica fluvial em uma bacia hidrográfica é muito importante, pois a partir dele, pode se planejar ações que contribua para a preservação dos canais, evitando assoreamento, diminuição do fluxo e extinção de canais fluviais. 
Revista Brasileira de Geografia Física v.11, n.04 (2018) 1490-1511

Cunha (1998) considera que a bacia hidrográfica é uma unidade geomorfológica muito importante por agrupar vários fatores em interação, tais como: bióticos, abióticos, econômicos e sociais. Intervenções expressivas, principalmente de origem antrópica, em qualquer parte de uma bacia, geram alterações cujos impactos serão transferidos a jusante, influenciando no fluxo energético e na dinâmica fluvial.

De acordo com Souza e Cunha (2012), a dinâmica fluvial de uma bacia hidrográfica reflete as inter-relações existentes entre as características dos elementos ambientais, tais como clima, geologia, cobertura vegetal, geomorfologia, solo e as formas de uso e cobertura da terra. Esses elementos, juntos, determinam o regime hidrológico através da quantidade de água e do tipo de sedimentos fornecidos à bacia.

O estudo das características ambientais de uma bacia hidrográfica é um instrumento de pesquisa que permite conhecer a sua estrutura e o seu funcionamento. Essas características estão relacionadas aos aspectos geológicos, às formas de relevo, aos processos geomorfológicos e às características hidrológicas e climáticas, assim como à biota e o uso da terra (Torres; Marques Neto; Menezes, 2012).

A área de uma bacia hidrográfica está sujeita ao trabalho dos rios, o que caracteriza a dinâmica fluvial, podendo ser dividida em erosão, transporte e sedimentação do material detrítico. A falta de manejo adequado do solo e a retirada indiscriminada da vegetação, bem como a urbanização acelerada próxima dos rios, podem comprometer a dinâmica fluvial natural da bacia hidrográfica e provocar danos irreversíveis no sistema que a circunda.

Como destacado anteriormente, a dinâmica fluvial é considerada como sendo a remoção, o transporte e a deposição das partículas envolvidas em toda a rede de drenagem, incidindo diretamente no equilíbrio do sistema fluvial. Quando ocorrem distúrbios no sistema, o canal vai ajustando-se e reajustando-se até encontrar um novo equilíbrio (Christofoletti, 1981).

No estudo das características hidrodinâmicas, deve-se incluir a variação do nível da água, turbulência, ação das ondas e as variações da velocidade. A contínua variação do nível do rio é considerada como um dos fatores mais importantes na erosão marginal, pois controla a atuação das forças de origem fluvial sobre os materiais das margens. Essas forças são representadas pelas ondas e correntes (Fernandez, 1990).
Alguns trabalhos internacionais sobre a dinâmica fluvial são relevantes: Chien (1985); Peter e Andrew (2001), Humphries et al. (2010), Balthazar et al. (2012) Mobaraki et al. (2012) Ramonell et al. (2014). Também os trabalhos de Orfeo e Stevaux (2002), que estudaram as características hidráulicas e morfológicas do alto e médio curso do rio Paraná (Argentina e Brasil), os de Quinlan et al., (2014), que estudaram os impactos de pequena escala na regulação de fluxo na dinâmica sedimentar do rio Ehen, no Reino Unido.

No Brasil, sobre as mudanças morfológicas e o processo de sedimentação, destacam-se os seguintes trabalhos: Souza (2004), Assine e Silva (2009), Silva (2009), Justiniano e Souza (2010); Grizio e Souza Filho, 2010; Silva et al. (2012); Leandro, Souza e Chaves (2012); Souza et al. (2015); e Sousa et al. (2017).

O estudo sobre a dinâmica fluvial na bacia hidrográfica do rio Carapá foi necessário, uma vez que o rio é a fonte principal de abastecimento de água potável à população urbana de Colíder, o recurso também é usado na zona rural para a produção de hortifrutigranjeiro, agricultura e pecuária. As informações geradas poderão subsidiar políticas públicas que comtemple a gestão da bacia.

Nesse contexto o presente estudo teve como objetivo analisar a dinâmica fluvial na bacia hidrográfica do rio Carapá em Colíder e Nova Canaã do Norte - MT.

\section{Materiais e métodos \\ Área de estudo}

A bacia hidrográfica do rio Carapá localizase entre as coordenadas geográficas de $10^{\circ} 21^{\prime} 50^{\prime \prime}$ a

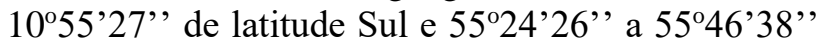
longitude Oeste. Possui suas nascentes nas bordas do Planalto dos Parecis e seus canais percorrem a Depressão Interplanáltica da Amazônia Meridional no sentido sul-norte, tendo sua foz na confluência com o rio do Meio, dando origem ao rio Parado, que, por sua vez, deságua no rio Teles Pires. Sua área encontra-se no território dos municípios de Colíder e Nova Canaã do Norte (Figura 1).

A área de estudo começou a ser colonizada na década de 1970, após a abertura da rodovia BR163 , em um processo impulsionado pelos projetos de colonização oficial e particular do governo federal. Para garantir a posse da terra, os colonizadores e os primeiros moradores, oriundos em grande maioria da região Sul do país, ocuparam e desmataram a área entre o rio Carapá e o Jacaré para a prática de agricultura diversificada (OLIVEIRA, 1998). 


\section{Procedimentos metodológicos}

$\mathrm{O}$ estudo da dinâmica fluvial foi realizado em seções ao longo do perfil longitudinal do canal principal e na foz do rio Jaracatiá, seu principal afluente da margem direita, envolvendo a descrição geral das seções: verificação da largura; profundidade do canal; velocidade do fluxo; vazão; erosão; analise granulométrica dos sedimentos das margens, do fundo e dos transportados em suspensão. Métodos semelhantes foram utilizados por Cunha (2010), Silva (2012), Leandro, Souza e Nascimento (2014), Almeida, et al. (2014).

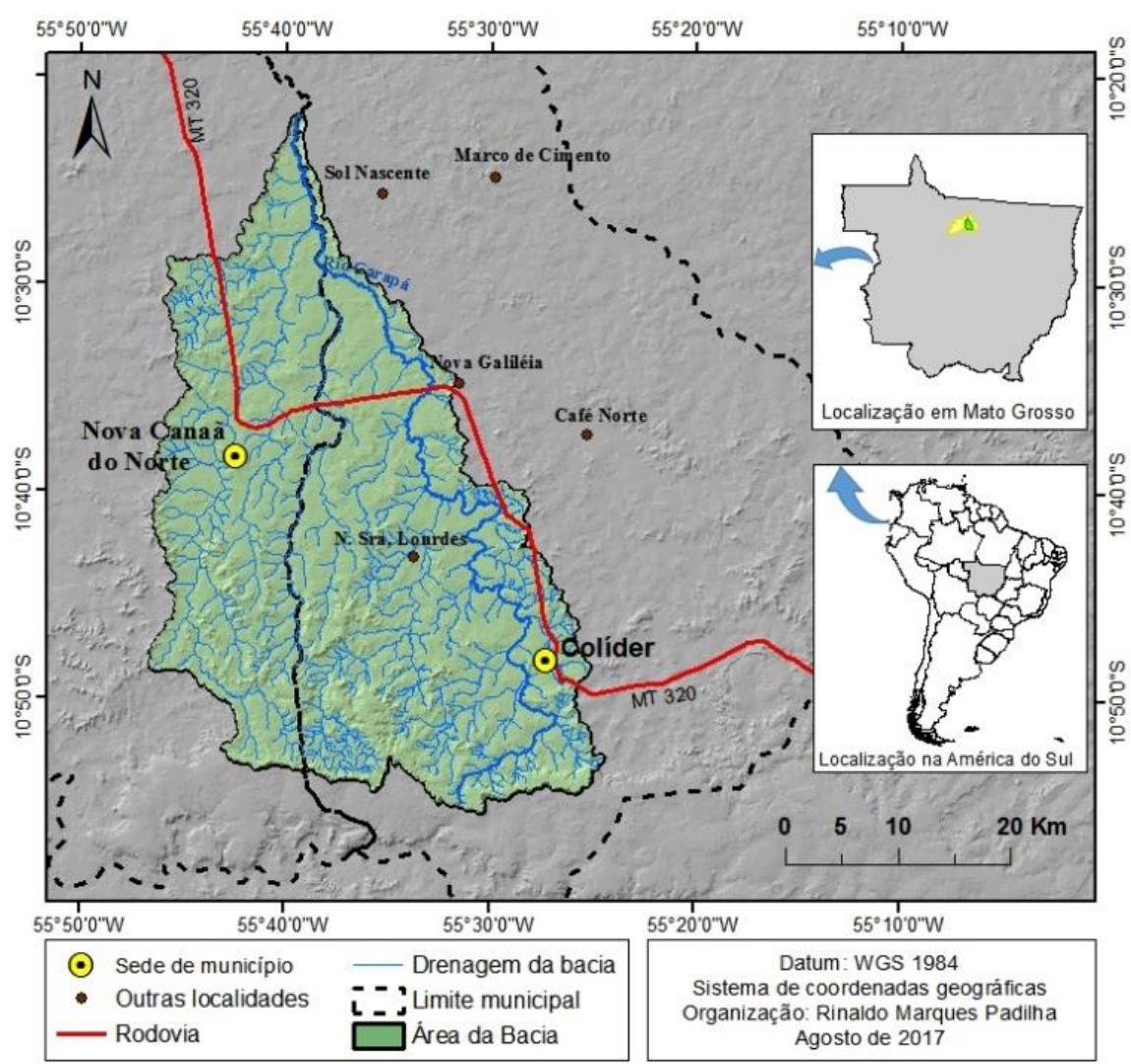

Figura 1 - Localização da bacia hidrográfica do rio Carapá. Elaborado pelo autor.

A escolha das seções ao longo do perfil longitudinal foi com base na compartimentação da bacia (alto, médio e baixo curso do rio Carapá). Em alguns trechos específicos foram escolhidos mais de uma seção devido sua representatividade na bacia como a montante e a jusante da área da captação de água para abastecimento de Colíder, e a confluência com o rio Jaracatiá, esse por ser o principal afluente pela margem esquerda e por atravessar toda a área urbana do município de Colíder, onde sofreu grandes alterações morfológicas.

$\mathrm{O}$ monitoramento $\mathrm{e}$ as coletas foram realizadas em três etapas. A primeira ocorreu nos dias 14 e 15 do mês de julho de 2016, para a primeira coleta de sedimentos de fundo, margem, suspensão e monitoramento das variáveis hidrodinâmicas (velocidade, profundidade e largura) e fixação dos pinos e estacas. A segunda etapa se realizou nos dias 28 e 29 de dezembro de 2016 para a segunda coleta de sedimentos de fundo e suspensão e monitoramento das variáveis hidrodinâmicas. A terceira etapa ocorreu entre os dias 29 e 30 de maio e 03 de junho de 2017, onde foram observados os pinos e as estacas e mensurado a erosão das margens.

\section{Monitoramento das variáveis hidrodinâmicas (batimetria)}

A velocidade do fluxo do rio foi obtida de acordo com Cunha (2010), utilizando flutuadores, trena e cronômetro. $\mathrm{O}$ processo consistiu em selecionar um trecho retilíneo do rio com, no mínimo, 10 metros de percurso livre de vegetação ou qualquer obstáculo que pudesse tocar o flutuador durante o seu percurso. O flutuador foi solto na água e foi medido utilizando cronómetro o tempo que ele levou para percorrer os 10 metros. O procedimento foi repetido 3 vezes sem contar as vezes que o flutuador tocou a margem. 
Para mensurar a largura do canal foi utilizada trena de 30 metros, esticada de uma extremidade do canal ao outro. Foi medida a largura do canal ao nível da água e a margem plena, que é o limite atingido pela água no período chuvoso.

Para determinar a profundidade do canal foi utilizada trena nas áreas de pequenas profundidades onde era possível caminhar no leito do rio. Para as áreas de profundidade acima de 1,50 onde o acesso só era possível com barco, foi utilizado o Ecobatimetro GPS Garmin Fishfinder 350C.

As medições de profundidade foram realizadas dividindo o perfil transversal em vários pontos, com distâncias iguais entre cada ponto podendo variar entre 0,70 metros até 2,00 metros, dependendo da largura da seção do canal. Essa técnica foi necessária para determinar a área da seção e possibilitar a construção do desenho do perfil transversal do canal.

Coleta de sedimentos de fundo, margem e suspensão

A coleta de sedimentos de fundo foi realizada utilizando draga do tipo Van Veen (amostrador de mandíbulas). A draga era arremessada da beira do barranco ou de cima do barco e içada com os sedimentos. As amostras foram armazenadas em sacolas plásticas transparentes de 1 kg e etiquetadas com dados sobre a localização para posterior análise granulométrica em laboratório.

Os sedimentos de margem foram coletados na face do barranco, com o auxílio de um enxadão que retirava uma amostra de sedimentos para determinar a granulometria e outra amostra em blocos de aproximadamente $20 \times 20 \mathrm{~cm}$, para análise de estabilidade de agregados. As amostras foram acondicionadas em sacolas plásticas devidamente etiquetadas com localização e descrição dos pontos.

Para coletar os sedimentos em suspensão foram utilizadas garrafas plásticas de um litro, que foram enxaguadas duas vezes com a água do próprio rio. Posteriormente as garrafas foram enchidas, devidamente etiquetadas e acondicionadas em caixas térmicas com gelo para encaminhamento ao laboratório e posterior análise.

\section{Monitoramento da erosão}

O monitoramento dos processos erosivos nas margens do rio Carapá foi realizado com a fixação de pinos de ferro e estacas de madeira. Essa técnica foi discutida e amplamente revisada por Thorne (1981), Silva (2009), Anstead (2012), Kuehn (2015) entre outros.
Pinos - foram fixados de dois a quatro pinos (dependendo da altura do barranco) na margem do rio. Os pinos de vergalhão tinham $50 \mathrm{~cm}$ de comprimento e $8 \mathrm{~mm}$ de diâmetro e foram fixados no sentido vertical no barranco da margem com o auxílio de marreta. A fixação ocorreu no período de estiagem no mês de julho de 2016, sendo deixado 10 cm do pino exposto para quantificar a erosão marginal, o que foi realizado no final do período chuvoso.

Estacas - foram utilizadas estacas de madeira para garantir o monitoramento da erosão na possibilidade de os pinos serem levados pela própria erosão da margem do rio. Em todos os locais de instalação de pinos foi fixada uma estaca de madeira de $45 \mathrm{~cm}$ de comprimento, distante dois metros da margem do rio, deixando $10 \mathrm{~cm}$ da estaca exposto, para facilitar sua localização e a dos pinos no barranco da margem.

\section{Análise de laboratório}

Análise dos sedimentos de fundo e margempara o fracionamento do material, foi utilizado o método de Dispersão Total - pipetagem e peneiramento (EMBRAPA, 1997). Os procedimentos tiveram as seguintes etapas:

Após a coleta, as amostras foram submetidas à secagem a $105^{\circ} \mathrm{C}$ em estufa modelo TE-394/2. As amostras secas foram destorroadas, separando $20 \mathrm{~g}$ de sedimentos de cada ponto, acondicionados em béquer de $250 \mathrm{ml}$ contendo $10 \mathrm{ml}$ de solução dispersante (NaOH N. 0,1M.L-1) e adicionando 100 $\mathrm{ml}$ de água destilada. Em seguida, o conteúdo dos béqueres foi agitado com um bastão de vidro e tampado com um vidro de relógio, sendo deixado em repouso por uma noite.

Transcorrido o período de repouso, as amostras foram novamente agitadas mecanicamente durante 15 minutos no Agitador de Wagner TE-160. Na sequência, o material foi lavado em uma peneira de $20 \mathrm{~cm}$ de diâmetro e malha de 0,053 ( $\left.\mathrm{n}^{\mathrm{o}} 270\right)$. As frações de areia grossa, média e fina ficaram retidas na peneira e as frações silte e a argila foram transportadas para uma proveta que foi completada com água até atingir $1000 \mathrm{ml}$.

O material da proveta foi agitado com um bastão de vidro por 30 segundos e deixado em repouso conforme tabela de temperatura e tempo de sedimentação. Transcorrido o tempo de sedimentação, foi introduzida uma pipeta no interior da proveta até a profundidade de $5 \mathrm{~cm}$, em seguida aspirada a suspensão com a fração argila. 
Ao fim do processo, tanto o material da pipeta (suspensão coletada) quanto da peneira foi transferido para béqueres de peso conhecido e identificados de acordo com o ponto de coleta e levados a estufa modelo TE-394/2 a $110^{\circ} \mathrm{C}$.

Concluída a secagem, o material mais grosseiro foi retirado para a etapa de fracionamento enquanto a argila foi pesada em balança analítica modelo AUY-220, subtraindo o peso do béquer, obtendo assim o peso da argila. A fração silte equivalerá à diferença da soma areia/argila das $20 \mathrm{~g}$ iniciais. Foram realizados três ensaios por ponto de coleta para obtenção da composição média do material de fundo e das margens.

$\mathrm{O}$ material grosseiro retido na peneira de malha de 0,053 ( $\mathrm{n}^{\mathrm{o}}$ 270) e seco na estufa, posteriormente passou pelo ensaio de peneiramento, que consiste em ser agitado mecanicamente no agitador de peneiras eletromagnético por 15 minutos. As amostras passaram por uma sequência de peneiras padronizadas para fracionamento em areia grossa, média e fina (Suguio, 1973).

No fracionamento, a areia retida na peneira de $2 \mathrm{~mm}$ foi considerada grossa; aquela que passou pela peneira de $2 \mathrm{~mm}$, mas ficou retida nas peneiras de $1,18 \mathrm{~mm}$ e $0,6 \mathrm{~mm}$ foi considerada média e, finalmente, a areia que passou pela peneira de 0,6 $\mathrm{mm}$ mas ficou retida nas peneiras de $0,075 \mathrm{~mm}$ e $0,053 \mathrm{~mm}$ foi classificada como fina.

Análise dos sedimentos em suspensão para a análise e quantificação dos sedimentos em suspensão foi utilizado o método de evaporação e pesagem. Esse método consiste transferir o conteúdo da garrafa plástica $(1.000 \mathrm{ml})$ para um béquer que havia sido pesado anteriormente, tomando o cuidado para que não ficasse sedimento em deposição no fundo e nas laterais da garrafa.

O béquer foi levado a estufa modelo TE$394 / 2$ com temperatura de $105^{\circ} \mathrm{C}$, para a evaporação total da água. Após a evaporação e o resfriamento o béquer foi pesado em balança analítica e a diferença entre o peso da tara com sedimentos e o peso do béquer pesado anteriormente foi obtido o peso do material da amostra. O béquer foi levado a estufa a $100^{\circ} \mathrm{C}$, sendo retirado e pesado novamente mais duas vezes para contra prova. Esses resultados são expressos em mg/L (Carvalho, 2008).

Análise de estabilidade de agregados - para medir a quantidade e a distribuição do tamanho dos agregados que são estáveis em água, relacionando-os com os que não desintegram pela tamisação, foi utilizado o método por via úmida (EMBRAPA, 1997).
Após a coleta em campo as amostras foram colocadas para secar ao ar. Quando secas foram destorroadas com as mãos cuidadosamente, quebrando os agregados maiores. Posteriormente as amostras foram passadas em peneira de $20 \mathrm{~cm}$ de diâmetro com abertura de malha de $4 \mathrm{~mm}$ e retida na de $2 \mathrm{~mm}$.

Foram pesadas 50 gramas em triplicata e colocada a primeira amostra em béquer de peso conhecido que foi levado para a estufa a $105^{\circ} \mathrm{C}$ por uma noite. Após esfriadas foram pesadas em balança analítica e seu peso foi utilizado para o cálculo do teor de agregados.

As outras duas amostras foram colocadas na parte superior de um conjunto de peneiras de $13 \mathrm{~cm}$ de diâmetro, uma em cada jogo, sobre disco de papel de filtro na seguinte ordem: $2 \mathrm{~mm} ; 1 \mathrm{~mm} ; 0,50 \mathrm{~mm}$, $0,25 \mathrm{~mm}$ e $0,10 \mathrm{~mm}$ de abertura de malha.

O nível da água foi ajustado no recipiente, de modo que os agregados contidos na peneira superior fossem umedecidos por capilaridade permanecendo assim por 4 minutos. Foi inclinado o papel de filtro e por meio de jatos de água foi deixado os agregados na peneira sem que os jatos os atingissem.

Foi ligado o aparelho de oscilação vertical graduado para uma amplitude de $4 \mathrm{~cm}$ de altura e uma frequência de 32 oscilações por minuto. Após agitar por 4 minutos, retirou-se os suportes contendo os jogos de peneiras, transferindo cada fração retida para os béqueres que já estavam numerados e com peso conhecido. As amostras foram colocadas em estufa a $105^{\circ} \mathrm{C}$ por uma noite. Posteriormente as frações foram pesadas em balança analítica.

Para calcular o teor de agregados retidos nas peneiras utilizou-se a seguinte expressão: Teor de agregados $=1000 .(\mathrm{a} / \mathrm{b})$.

Onde:

$\mathrm{a}=$ Peso do agregado a $105^{\circ} \mathrm{C}$.

$\mathrm{b}=$ Peso da amostra seca a $105^{\circ} \mathrm{C}$.

Teor de agregados $<0,10 \mathrm{~mm}=1000-$ soma dos teores de agregados.

As análises de estabilidade de agregados de solo nas margens foram realizadas no Laboratório de Pesquisa e Estudos em Geomorfologia Fluvial (LAPEGEOF) Sandra Baptista da Cunha, da Universidade do Estado de Mato Grosso (UNEMAT) Campus de Cáceres.

Pela proximidade com a localização da área da pesquisa, as análises granulométricas de sedimentos de fundo, margem e suspensão foram realizadas no Laboratório de Pesquisa e Estudos em 
Geomorfologia Fluvial (LAPEGEOF) Antônio Christofoletti, da Universidade do Estado de Mato Grosso (UNEMAT), Campus de Colíder.

\section{Trabalho de Gabinete}

Velocidade do fluxo - para mensurar a velocidade, medida através dos flutuadores, foi utilizada a equação: $\mathrm{V}=\mathrm{D} / \mathrm{T}$ (Cunha, 2010).

$$
\begin{aligned}
& \mathrm{V}=\text { Velocidade }-(\mathrm{m} / \mathrm{s}) . \\
& \mathrm{D}=\text { Distância }-(\mathrm{m}) . \\
& \mathrm{T}=\text { Tempo }-(\mathrm{s}) .
\end{aligned}
$$

De acordo com Cunha (2010) a velocidade média do rio em uma seção vertical é 0,85 vez a velocidade da superfície, pois a velocidade da água é variável, decrescendo com a profundidade e na direção das margens, devido às forças de fricção entre o fluxo de água e as paredes laterais ou fundo do canal. Sendo assim, foi multiplicado o resultado da equação por 0,85 . Dessa forma, temos a fórmula $(\mathrm{V}=\mathrm{D} / \mathrm{T} \cdot 0,85)$.

Cálculo da área (seção transversal) - para calcular a área na seção transversal no nível de margens plenas e área da seção molhada foi adotada a fórmula: $\mathrm{A}=\mathrm{L} \times \mathrm{P}$ (Cunha, 2010).

$$
\begin{aligned}
& \mathrm{A}=\text { Área da seção }-\left(\mathrm{m}^{2}\right) . \\
& \mathrm{L}=\text { Largura do canal }-(\mathrm{m}) . \\
& \mathrm{P}=\text { Profundidade média }-(\mathrm{m}) .
\end{aligned}
$$

Cálculo de vazão - para obter o cálculo da vazão foi utilizada a seguinte fórmula: $\mathrm{Q}=\mathrm{A} \times \mathrm{V}$ (Cunha, 2010).

$$
\begin{aligned}
& \mathrm{Q}=\text { Vazão }-\left(\mathrm{m}^{3} / \mathrm{s}\right) . \\
& \mathrm{A}=\text { Área }-\left(\mathrm{m}^{2}\right) . \\
& \mathrm{V}=\text { Velocidade da água }-(\mathrm{m} / \mathrm{s}) .
\end{aligned}
$$

Descarga sólida em suspensão - para determinar a descarga sólida em suspensão que é transportada diariamente pelo rio, foi utilizada a formula: Qss = Css x Q x 0,0864 (Carvalho, et al. 2000).

Qss = Descarga sólida em suspensão em toneladas por dia (t/dia).

Css = Concentração de sedimentos em suspensão em miligramas por litro (mg/L).
$\mathrm{Q}=$ Vazão ou descarga liquida em metros cúbicos por segundos $\left(\mathrm{m}^{3} / \mathrm{s}\right)$.

Sedimentos grosseiros - para medir o tamanho médio das partículas grosseiras como blocos, seixos e matacões, usou-se a fórmula $\frac{a+b+c}{3}$ (Cunha, 2010).

$$
\begin{aligned}
& \mathrm{a}=\text { Eixo de maior comprimento. } \\
& \mathrm{b}=\text { Eixo de maior largura. } \\
& \mathrm{c}=\text { Eixo de maior altura. }
\end{aligned}
$$

Quantificação da magnitude da erosão marginal - a quantificação da magnitude da erosão marginal, após a medição, foi calculada utilizandose a seguinte fórmula: $E m=\left(\mathrm{L}_{1}-\mathrm{L}_{0}\right) / \mathrm{t}$ (Fernandez, 1996). cm/mês);

$$
\text { Em = Magnitude da erosão }(\mathrm{cm} / \text { dia ou }
$$
erosão $(\mathrm{cm})$;

$$
\mathrm{L}_{1}=\text { Comprimento do pino exposto pela }
$$

$\mathrm{L}_{0}=$ Comprimento do pino exposto

inicialmente, padronizada em $10 \mathrm{~cm}$;

$$
\mathrm{t}=\text { Tempo transcorrido (dias ou meses). }
$$

\section{Resultados e discussão}

A bacia hidrográfica do rio Carapá possui a área territorial de $1409,121 \mathrm{~km}^{2}$, sendo classificada em sua grandeza espacial como uma grande bacia. De acordo com Christofoletti (1999), as grandes bacias hidrográficas possuem área superior a 1.000 $\mathrm{km}^{2}$. A bacia tem o padrão de drenagem exorréica, ou seja, o seu escoamento é de forma contínua e toda a sua água tem como destino final o oceano.

Os primeiros quilômetros de percurso do rio principal possuem padrão meandrante encaixado. Percorre as bordas do Planalto dos Parecis em região com altitudes superiores a 350 metros e declives acentuados até entrar na Depressão Interplanáutica da Amazônia Meridional, percorrendo cerca de 150 $\mathrm{km}$ em relevo com baixa declividade. O canal passa a ser sinuoso divagante em maior parte de seu trajeto; porém, em alguns trechos, o rio apresenta padrão irregular (Figura 2 e 3 ). 
Revista Brasileira de Geografia Física v.11, n.04 (2018) 1490-1511

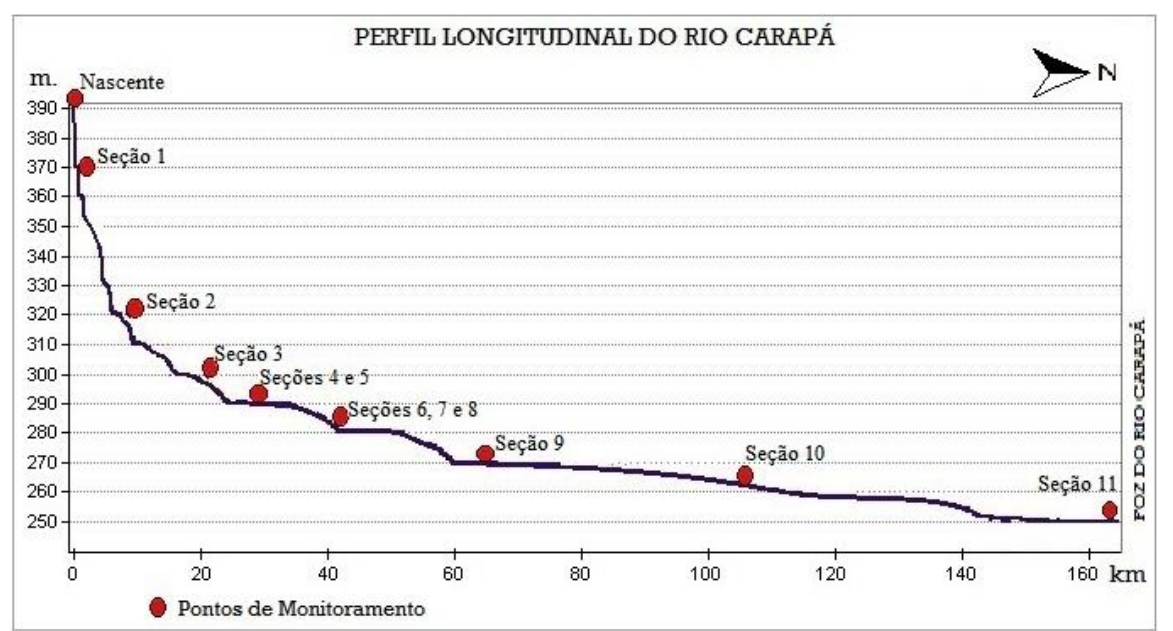

Figura 2 - Perfil longitudinal do rio Carapá. Elaborado pelo autor.

Foram monitorados nove segmentos ao longo do perfil longitudinal (Figura 2 e 3 ), totalizando 11 seções com informações sobre largura e profundidade do canal, velocidade do fluxo, vazão, transporte de sedimentos de fundo e suspensão, erosão e sedimentação.

\section{Trecho 1}

O trecho 1 refere-se à área da nascente do rio Carapá, trata-se de uma vereda (área úmida com buritizais) que abrange aproximadamente $0,05 \mathrm{~km}^{2}$. Seu entorno encontra-se desmatado e é utilizado para a prática da pecuária extensiva. Conforme o Manual Técnico de Geomorfologia IBGE (2009), a vereda pode ser classificada como uma zona deprimida de forma ovalada, linear ou digitiforme, dentro de área estruturalmente plana ou aplanada por erosão. É assinalada por vegetação típica, caracterizada por palmeiras de diferentes espécies, particularmente buritis e outras plantas indicadoras de umidade como açaí e capim redondo. $\mathrm{Na}$ área da nascente, possui acúmulo de água, formando uma lagoa a montante.

A concentração de sedimentos em suspensão (Css) na nascente foi de $12 \mathrm{mg} / \mathrm{L}$ no período de estiagem, e de $16 \mathrm{mg} / \mathrm{L}$ no período chuvoso.

A área apresenta pisoteio do gado, usada para dessedentação diretamente da nascente, alterando de forma constante a morfologia da vereda, podendo comprometer no futuro a manutenção do fluxo de água dos primeiros quilômetros do canal.

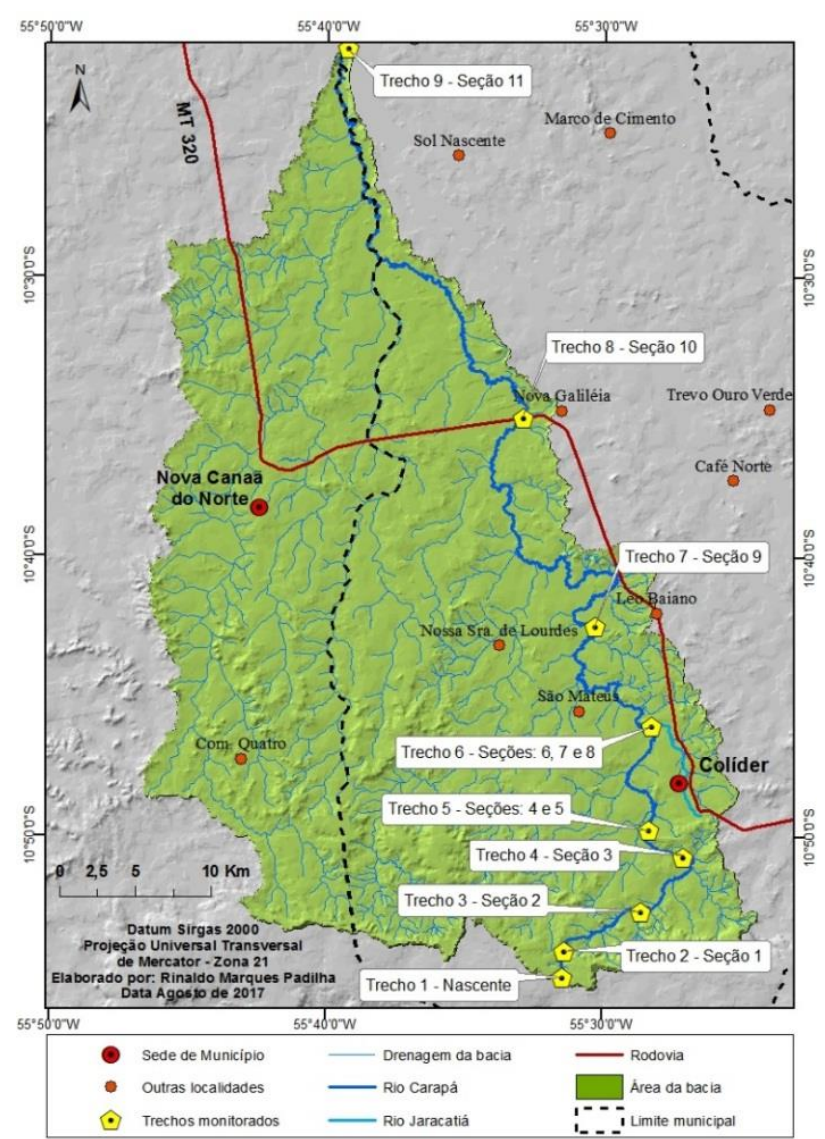

Figura 3 - Localização dos trechos e seções de monitoramento. Rios Carapá e Jaracatiá. Fonte: Elaborado pelo autor.

\section{Trecho 2}

A primeira seção encontra-se no trecho 2 . Na seção 1, o leito é encaixado, em formato de "U", com padrão sinuoso, com afloramento rochoso no fundo, propiciando a formação de corredeiras que também são obstáculos para o fluxo no período de estiagem (Figura 4).

A vegetação do entorno é composta por espécies arbóreas, arbustivas com uma grande 
variedade de cipós. Ela está presente em aproximadamente 5 a 6 metros em cada lado da margem do canal, existindo trilhas feitas pelo gado para ter acesso a água. Nesse segmento, foi selecionada a primeira a seção transversal.
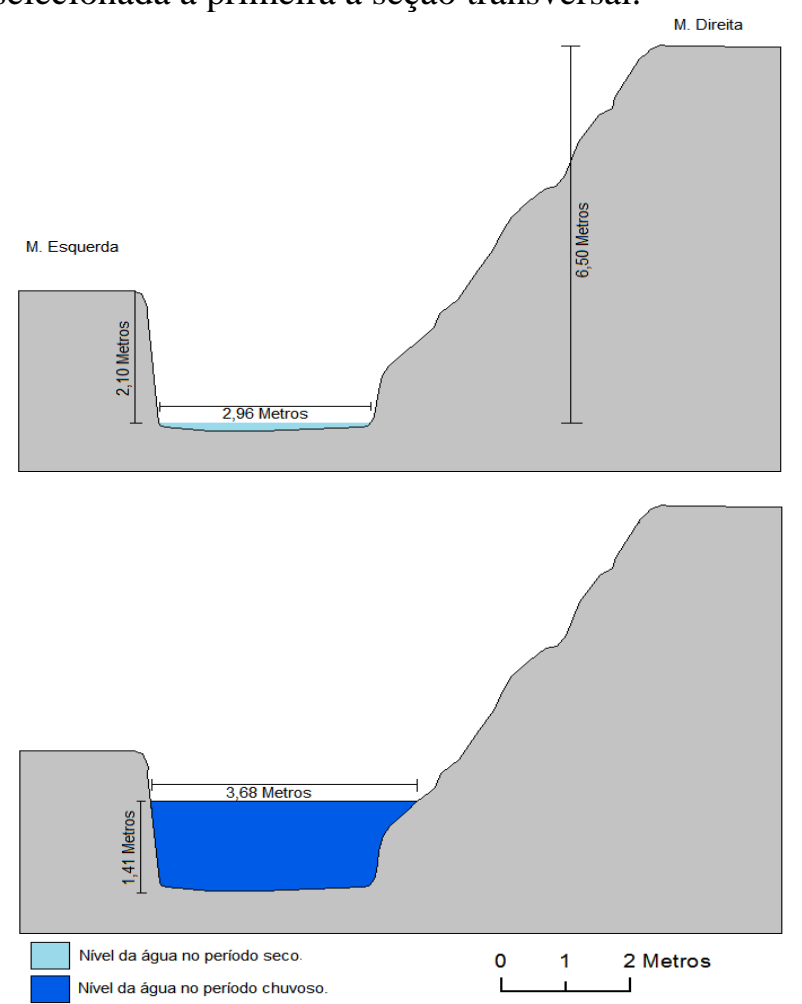

Figura 4 - Perfil transversal da seção 1 - Rio Carapá, 2016. Elaborado pelo autor.
$\mathrm{Na}$ primeira seção, os sedimentos da margem são constituídos de materiais finos, com predomino de silte $51,99 \%$ seguido da areia fina $41,86 \%$ (Tabela 1). O teor de agregados estáveis em água registrou que 55,08\% sendo compostos de agregados maiores de 2,00 $\mathrm{mm}$. Esse percentual evidencia que são solos pouco susceptíveis à erosão.

A magnitude de erosão obtida pela técnica de pinos ficou entre 0,07 a $0,11 \mathrm{~cm} / \mathrm{mês}$ e a maior erosão acumulada para o período foi de $1,2 \mathrm{~cm}$, observada no pino mais distante da lâmina de água (Tabela 2). O baixo valor de erosão acumulada corrobora com os índices de estabilidade de agregados para a seção, que apresentou $55,08 \%$ de partículas com tamanhos maiores que $2,00 \mathrm{~mm}$ (Tabela 3). De acordo com Chaves e Calegari (2001), quanto maior a agregação e a estabilidade dos sedimentos, maior a resistência à erosão hídrica.

Oliveira (2006), concluiu que a erosão da margem depende, sobretudo, das características do barranco (altura, geometria, estrutura, propriedades mecânicas de seus constituintes).

Tabela 1 - Granulometria dos sedimentos de margem - julho de 2016.

\begin{tabular}{c|c|c|c|c|c|c}
\hline \multirow{2}{*}{ Trecho } & Seção & $\begin{array}{c}\text { Areia } \\
\text { Grossa } \%\end{array}$ & $\begin{array}{c}\text { Areia Média } \\
\%\end{array}$ & $\begin{array}{c}\text { Areia fina } \\
\%\end{array}$ & Silte \% & Argila \% \\
\hline 1 & Nascente & --- & --- & --- & --- & --- \\
\hline 2 & 1 & 2,36 & 1,16 & 41,86 & 51,99 & 2,65 \\
\hline 3 & 2 & 0,00 & 0,21 & 28,51 & 67,90 & 3,39 \\
\hline 4 & 3 & 0,15 & 1,02 & 56,81 & 39,93 & 2,09 \\
\hline 5 & 4 & --- & --- & -- & --- & --- \\
\hline 5 & 5 & 0,00 & 3,33 & 63,54 & 30,91 & 2,23 \\
\hline 6 & 6 & 23,32 & 10,14 & 25,31 & 37,08 & 4,16 \\
\hline 6 & 7 & 14,63 & 5,16 & 14,72 & 61,44 & 4,06 \\
\hline 6 & 8 & --- & --- & --- & --- & --- \\
\hline 7 & 9 & 0,00 & 0,00 & 25,01 & 71,17 & 3,82 \\
\hline 8 & 10 & 4,27 & 4,68 & 29,58 & 56,35 & 5,13 \\
\hline 9 & 11 & 0,00 & 0,00 & 75,79 & 22,32 & 1,89 \\
\hline
\end{tabular}

Elaborado pelo autor.

Na primeira seção transversal, no período de estiagem, a velocidade do fluxo foi de $0,19 \mathrm{~m} / \mathrm{s}$, a área de seção molhada era de $0,248 \mathrm{~m}^{2}$ e a vazão de
$0,047 \mathrm{~m}^{3} / \mathrm{s}$. No período chuvoso, a área da seção molhada era de $4,434 \mathrm{~m}^{2}$, a velocidade do fluxo registrou $0,49 \mathrm{~m} / \mathrm{s}$ e a vazão $2,174 \mathrm{~m}^{3} / \mathrm{s}$ (Tabela 4 ). 
Revista Brasileira de Geografia Física v.11, n.04 (2018) 1490-1511

Tabela 2 - Monitoramento de erosão por pinos e estacas - 2016/2017.

\begin{tabular}{|c|c|c|c|c|c|c|c|c|}
\hline \multirow[b]{2}{*}{ Trecho } & \multirow[b]{2}{*}{ Seção } & \multirow[b]{2}{*}{$\begin{array}{l}N^{o} \text { de } \\
\text { Pinos }\end{array}$} & \multirow[b]{2}{*}{$\begin{array}{l}\text { Período } \\
\text { (Meses) }\end{array}$} & \multicolumn{4}{|c|}{ Pinos de erosão } & \multirow{2}{*}{$\begin{array}{c}\text { Estacas } \\
\text { Recuo da } \\
\text { margem } \\
(\mathrm{cm})\end{array}$} \\
\hline & & & & $\begin{array}{c}\text { Exposição } \\
\text { inicial } \\
\text { Jul/2016 } \\
(\mathrm{cm})\end{array}$ & $\begin{array}{c}\text { Exposição } \\
\text { final Mai- } \\
\text { jun/2017 } \\
(\mathrm{cm})\end{array}$ & $\begin{array}{c}\text { Erosão } \\
\text { Acumulada } \\
(\mathrm{cm})\end{array}$ & $\begin{array}{l}\text { Magnitude } \\
\text { da erosão } \\
(\mathrm{cm} / \mathrm{mês})\end{array}$ & \\
\hline 1 & Nascen & --- & ---- & --- & ---- & ---- & ---- & ---- \\
\hline \multirow{2}{*}{2} & \multirow{2}{*}{1} & 1 & 10,5 & 10 & 10,8 & 0,8 & 0,07 & \multirow{2}{*}{---} \\
\hline & & 2 & 10,5 & 10 & 11,2 & 1,2 & 0,11 & \\
\hline \multirow{2}{*}{3} & \multirow{2}{*}{2} & 1 & 10,5 & 10 & 11,3 & 1,3 & 0,12 & \multirow{2}{*}{---} \\
\hline & & 2 & 10,5 & 10 & 12,1 & 2,1 & 0,20 & \\
\hline \multirow{2}{*}{4} & \multirow{2}{*}{3} & 1 & 10,5 & 10 & 15 & 5 & 0,47 & \multirow{2}{*}{2} \\
\hline & & 2 & 10,5 & 10 & 12 & 2 & 0,19 & \\
\hline 5 & 4 & --- & --- & --- & --- & --- & --- & --- \\
\hline \multirow{2}{*}{5} & \multirow{2}{*}{5} & 1 & 10,5 & 10 & 12,8 & 2,8 & 0,26 & \multirow{2}{*}{---} \\
\hline & & 2 & 10,5 & 10 & 13,1 & 3,1 & 0,29 & \\
\hline \multirow{2}{*}{6} & \multirow{2}{*}{6} & 1 & 10,5 & 10 & 10,6 & 0,6 & 0,05 & \multirow{2}{*}{---} \\
\hline & & 2 & 10,5 & 10 & 10,4 & 0,4 & 0,03 & \\
\hline \multirow{2}{*}{6} & \multirow{2}{*}{7} & 1 & 10,5 & 10 & 12,1 & 2,1 & 0,20 & \multirow{2}{*}{3} \\
\hline & & 2 & 10,5 & 10 & 11,8 & 1,8 & 0,17 & \\
\hline 6 & 8 & --- & --- & --- & --- & --- & --- & --- \\
\hline \multirow{2}{*}{7} & \multirow{2}{*}{9} & 1 & 10,5 & 10 & Removido & --- & --- & \multirow{2}{*}{30} \\
\hline & & 2 & 10,5 & 10 & Removido & --- & --- & \\
\hline \multirow{2}{*}{8} & \multirow{2}{*}{10} & 1 & 10,5 & 10 & 11,9 & 1,9 & 0,18 & \multirow{2}{*}{2} \\
\hline & & 2 & 10,5 & 10 & 10,5 & 0,5 & 0,04 & \\
\hline \multirow{4}{*}{9} & \multirow{4}{*}{11} & 1 & 10,5 & 10 & Submerso & --- & --- & \\
\hline & & 2 & 10,5 & 10 & 18,4 & 8,4 & 0,80 & 10 \\
\hline & & 3 & 10,5 & 10 & 21 & 11 & 1,04 & 10 \\
\hline & & 4 & 10,5 & 10 & 19,3 & 9,3 & 0,88 & \\
\hline
\end{tabular}

Elaborado pelo autor.

Tabela 3 - Estabilidade de agregados dos sedimentos de margem (\%) - julho de 2016.

\begin{tabular}{c|c|c|c|c|c|c|c}
\hline \multirow{2}{*}{ Trecho } & \multirow{2}{*}{ Seção } & \multicolumn{7}{|c}{ Tamanho $(\mathrm{mm})$} \\
\cline { 3 - 8 } & & $2,00 \mathrm{a} 4,00$ & 1,00 a 2,00 & 0,50 a 1,00 & 0,25 a 0,50 & 0,10 a 0,25 & $<0,10$ \\
\hline 1 & Nascente & --- & --- & --- & --- & --- & --- \\
\hline 2 & 1 & 55,08 & 14,64 & 13,97 & 9,65 & 5,07 & 1,58 \\
\hline 3 & 2 & --- & --- & --- & --- & --- & --- \\
\hline 4 & 3 & 43,53 & 14,56 & 20,71 & 11,58 & 6,21 & 3,41 \\
\hline 5 & 4 & --- & --- & --- & --- & --- & --- \\
\hline 5 & 5 & 20,91 & 10,51 & 7,40 & 24,01 & 26,91 & 10,27 \\
\hline 6 & 6 & 24,19 & 12,03 & 23,36 & 23,07 & 9,96 & 7,39 \\
\hline 6 & 7 & 28,86 & 8,50 & 12,11 & 11,21 & 17,46 & 21,87 \\
\hline 6 & 8 & --- & --- & --- & --- & --- & --- \\
\hline 7 & 9 & 3,27 & 6,08 & 12,03 & 27,41 & 28,11 & 23,10 \\
\hline 8 & 10 & 58,76 & 11,16 & 10,60 & 8,78 & 7,27 & 3,44 \\
\hline 9 & 11 & 6,48 & 6,21 & 20,64 & 27,65 & 24,95 & 14,07 \\
\hline
\end{tabular}

Elaborado pelo autor. 
Tabela 4 - Variáveis hidrodinâmicas das seções monitoradas.

\begin{tabular}{|c|c|c|c|c|c|c|c|}
\hline \multirow[b]{2}{*}{ Trecho } & \multirow[b]{2}{*}{ Seção } & \multicolumn{3}{|c|}{ Período de estiagem. Julho/2016. } & \multicolumn{3}{|c|}{ Período chuvoso. Dezembro/2016. } \\
\hline & & $\begin{array}{c}\text { Área seção } \\
\text { molhada em } \\
\mathrm{m}^{2}\end{array}$ & $\begin{array}{c}\text { Velocidade } \\
\mathrm{m} / \mathrm{s}\end{array}$ & Vazão m³/s & $\begin{array}{c}\text { Área seção } \\
\text { molhada em } \\
m^{2}\end{array}$ & $\begin{array}{c}\text { Velocidade } \\
\mathrm{m} / \mathrm{s}\end{array}$ & Vazão m³/s \\
\hline 1 & Nascente & -- & -- & -- & -- & -- & -- \\
\hline 2 & 1 & 0,248 & 0,190 & 0,047 & 4,434 & 0,490 & 2,174 \\
\hline 3 & 2 & 0,639 & 0,137 & 0,087 & 4,558 & 0,495 & 2,257 \\
\hline 4 & 3 & 1,512 & 0,173 & 0,262 & 7,227 & 0,500 & 3,613 \\
\hline 5 & 4 & 9,426 & -- & -- & 16,239 & -- & -- \\
\hline 5 & 5 & 6,915 & $* 0,286$ & $* 0,235$ & 14,778 & 0,289 & 4,282 \\
\hline 6 & 6 & 0,157 & 0,331 & 0,052 & 9,104 & 0,481 & 4,380 \\
\hline 6 & 7 & 3,327 & 0,113 & 0,378 & 12,670 & 0,510 & 6,462 \\
\hline 6 & 8 & 1,171 & 0,398 & 0,466 & 23,582 & 0,472 & 11,136 \\
\hline 7 & 9 & 7,262 & 0,093 & 0,680 & 36,746 & 0,750 & 27,559 \\
\hline 8 & 10 & 4,229 & 0,593 & 2,508 & 43,611 & 0,665 & 29,011 \\
\hline 9 & 11 & 11,591 & 0,331 & 3,838 & 103,350 & 0,728 & 75,297 \\
\hline
\end{tabular}

* Pela inexistência de fluxo, foram medidos 50 metros a jusante da seção. Elaborado pelo autor.

A granulometria dos sedimentos de fundo ficou assim distribuída no período de estiagem: $45,77 \%$ de areia grossa, $29,27 \%$ de areia fina e $19,35 \%$ de areia média. Os sedimentos mais finos representaram menor proporção $4,93 \%$ silte e $0,68 \%$ argila. No período chuvoso, o rio teve maior capacidade de transportar material grosseiro: $37,95 \%$ de areia grossa, 35,93\% de areia média e $21,49 \%$ de areia fina. Por se tratar de uma região de planalto, com uma declividade acentuada em relação aos demais pontos, foi favorecido o transporte de sedimentos grosseiros provenientes da erosão do próprio leito (Tabela 5).

Bayer e Carvalho (2008) constataram que, com relação à granulometria do material de fundo, o rio Araguaia transporta basicamente, no trecho entre o rio Crixás-Açu e a bifurcação Araguaia-Javaés, material arenoso de textura média. Nas margens, o rio apresenta, ao longo desse trecho, material muito fino (silte e argila).

Nessa seção, verificou-se a presença de material por rolamento, como seixos, blocos e matacões, principalmente no período chuvoso, quando a velocidade é maior, mostrando, assim, a capacidade e a competência de transportar sedimentos. Os tamanhos dos materiais variaram na seção (Figura 5), da esquerda para a direita: blocos com diâmetros de $210 \mathrm{~mm}, 155 \mathrm{~mm}, 125 \mathrm{~mm}, 80$ $\mathrm{mm}, 65 \mathrm{~mm}$ e seixo com diâmetro de $42,5 \mathrm{~mm}$.

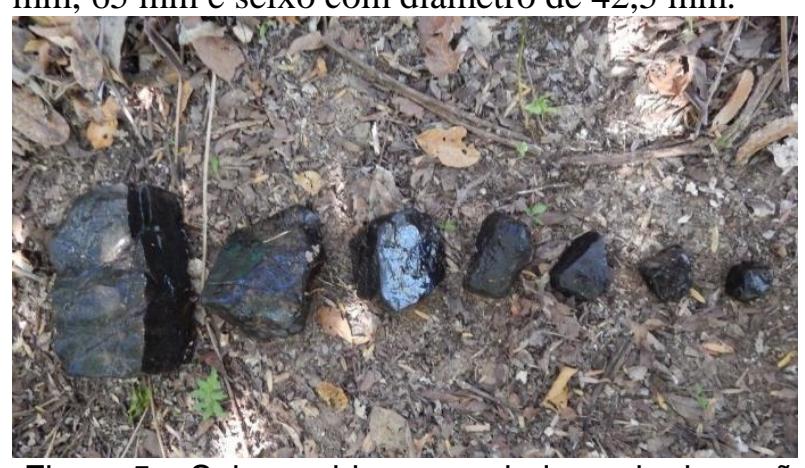

Figura 5 - Seixos e blocos arrolados pelo rio seção 1. Rio Carapá, Colíder 2016. Fonte o autor.

Quanto à concentração de sedimentos e à descarga solida suspensa, houve aumento de montante para jusante ao longo do perfil longitudinal. De acordo Souza et al. (2015), o aumento da concentração de sedimentos ao longo perfil longitudinal está associado à contribuição dos tributários e ao uso da terra.

A concentração dos sedimentos suspensos na primeira seção foi de $33 \mathrm{mg} / \mathrm{L}$ no período seco e de $34 \mathrm{mg} / \mathrm{L}$ no período chuvoso. A descarga sólida em suspensão (Qss) foi de $0,135 \mathrm{t} / \mathrm{dia}$ no período de estiagem e de 6,388 t/dia no período chuvoso (Tabela 6). 
Tabela 5 - Granulometria dos sedimentos de fundo. Períodos: estiagem jul/2016 e chuvoso dez/2016.

\begin{tabular}{|c|c|c|c|c|c|c|c|c|c|c|c|}
\hline \multirow{2}{*}{ Trecho } & \multirow{2}{*}{ Seção } & \multicolumn{2}{|c|}{ Areia Grossa \% } & \multicolumn{2}{|c|}{ Areia Média \% } & \multicolumn{2}{|c|}{ Areia Fina \% } & \multicolumn{2}{|c|}{ Silte $\%$} & \multicolumn{2}{|c|}{ Argila \% } \\
\hline & & Estiagem & \begin{tabular}{|l|} 
Chuva \\
\end{tabular} & Estiagem & Chuva & Estiagem & Chuva & Estiagem & Chuva & Estiagem & Chuva \\
\hline 1 & Nascente & -- & - & -- & -- & -- & -- & - & -- & - & -- \\
\hline 2 & 1 & 45,77 & 37,95 & 19,35 & 35,93 & 29,27 & 21,49 & 4,93 & 4,00 & 0,68 & 0,65 \\
\hline 3 & 2 & 35,60 & 7,73 & 17,64 & 28,48 & 38,19 & 58,91 & 7,91 & 4,24 & 0,66 & 0,64 \\
\hline 4 & 3 & 40,52 & 35,11 & 17,07 & 33,78 & 37,61 & 26,90 & 4,19 & 3,68 & 0,61 & 0,53 \\
\hline 5 & 4 & 6,44 & 6,85 & 2,99 & 10,72 & 32,43 & 40,00 & 55,14 & 39,25 & 3,01 & 3,19 \\
\hline 5 & 5 & 2,64 & 66,16 & 9,18 & 15,33 & 77,09 & 3,53 & 10,25 & 13,06 & 0,85 & 1,93 \\
\hline 6 & 6 & 41,06 & 36,90 & 30,19 & 46,43 & 26,08 & 14,02 & 2,25 & 1,94 & 0,42 & 0,71 \\
\hline 6 & 7 & 13,16 & 22,25 & 20,21 & 40,25 & 61,96 & 34,76 & 3,98 & 2,08 & 0,69 & 0,65 \\
\hline 6 & 8 & 75,74 & 25,77 & 13,53 & 58,54 & 9,72 & 15,07 & 0,34 & 0,05 & 0,68 & 0,58 \\
\hline 7 & 9 & 34,82 & 18,07 & 15,87 & 57,43 & 44,03 & 18,05 & 4,65 & 5,88 & 0,64 & 0,57 \\
\hline 8 & 10 & 4,05 & 24,89 & 19,91 & 19,23 & 74,83 & 31,25 & 0,51 & 23,60 & 0,70 & 1,02 \\
\hline 9 & 11 & 7,68 & 1,71 & 8,61 & 13,26 & 82,86 & 84,09 & 0,54 & 0,24 & 0,32 & 0,70 \\
\hline
\end{tabular}

Elaborado pelo autor.

Tabela 6 - Concentração de sedimentos em suspensão (Css). Descarga sólida em suspensão (Qss) - 2016.

\begin{tabular}{l|l|l|l|l|l}
\hline \multirow{2}{*}{ Trecho } & \multirow{2}{*}{ Seção } & \multicolumn{2}{|c}{ Css - mg/L } & \multicolumn{2}{c}{ Qss - t/dia } \\
\cline { 3 - 5 } & & Estiagem & Chuvoso & Estiagem & Chuvoso \\
\hline
\end{tabular}

\begin{tabular}{c|c|c|c|c|c}
\hline 1 & Nascente & 12 & 16 & -- & -- \\
\hline 2 & 1 & 33 & 34 & 0,135 & 6,388 \\
\hline 3 & 2 & 50 & 63 & 0,378 & 12,287 \\
\hline 4 & 3 & 41 & 73 & 0,929 & 22,793 \\
\hline 5 & 4 & 39 & 252 & -- & -- \\
\hline 5 & 5 & 49 & 136 & 0,834 & 50,319 \\
\hline 6 & 6 & 106 & 78 & 0,479 & 29,522 \\
\hline 6 & 7 & 61 & 55 & 1,996 & 30,708 \\
\hline 6 & 8 & 59 & 82 & 2,379 & 78,898 \\
\hline 7 & 9 & 59 & 39 & 3,471 & 92,866 \\
\hline 8 & 10 & 53 & 54 & 11,486 & 135,355 \\
\hline 9 & 11 & 60 & 61 & 19,899 & 396,850 \\
\hline & & Elaborad & \multicolumn{3}{|c}{}
\end{tabular}

Elaborado pelo autor.

Estudos realizados no rio Paraguai por Souza et al. (2017) mostraram que a concentração de sedimento em suspensão apresentou valores superiores em época da cheia. $\mathrm{O}$ aumento na quantidade de sedimentos finos em suspensão nesse período está relacionado ao alto índice pluviométrico que favorece o arrastamento de sedimentos e aumenta a quantidade desses materiais na calha do rio.

\section{Trecho 3}

Padilha, R. M., Souza, C. A.
No trecho 3 está a seção 2 e apresenta as Áreas de Preservação Permanente parcialmente preservadas com espécies arbóreas, arbustos, bananeiras e uma grande variedade de cipós trepadeiras e lianas lenhosas. São espécies bem características da Floresta Ombrófila Aberta Tropical - Formação Submontana com cipó.

Na segunda seção, o canal é irregular e apresenta sua margem esquerda escarpada; a margem direita apresenta-se rampeada, com grande potencial de erosão (Figura 6). No período de estiagem, a área de seção molhada era de 0,639 m², a velocidade do fluxo foi de $0,137 \mathrm{~m} / \mathrm{s}$ e a vazão encontrada foi de $0,087 \mathrm{~m}^{3} / \mathrm{s}$. No período chuvoso, a área de seção molhada aumentou para $4,558 \mathrm{~m}^{2}$, a velocidade do fluxo aumentou para $0,495 \mathrm{~m} / \mathrm{s}$ e a vazão para de $2,257 \mathrm{~m}^{3} / \mathrm{s}$ (Tabela 4).
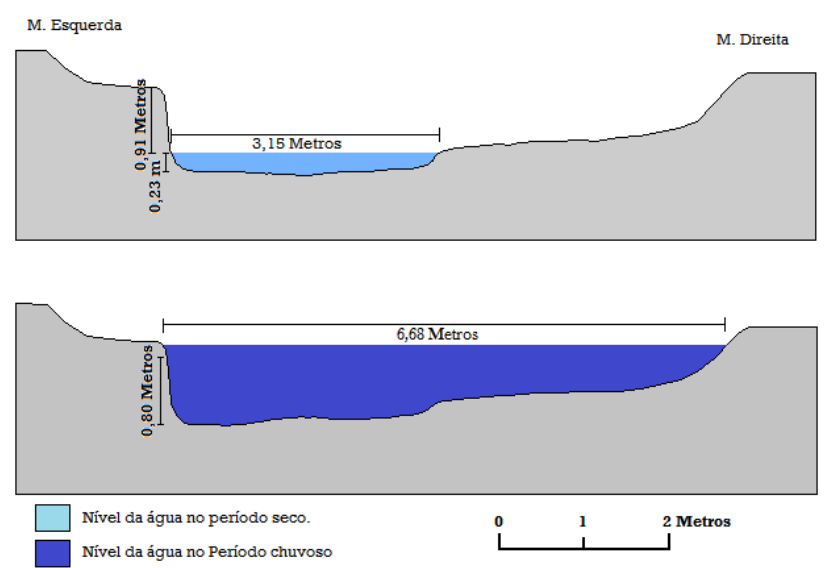

Figura 6 - Perfil transversal da seção 2. Rio Carapá, 2016. Elaborado pelo autor. 
A análise granulométrica do material da margem mostrou a predominância de sedimentos finos, 67,9\% de silte e 3,39\% de argila. A fração de areia grossa e média não alcançou $0,3 \%$. Mesmo tendo apresentado baixo percentual de areia, a seção registrou uma erosão maior que a seção 1 , sendo registrados valores entre 0,12 a $0,20 \mathrm{~cm} / \mathrm{mês}$ e erosão acumulada de $2,1 \mathrm{~cm}$ para o período (Tabela 2).

Estudo realizado na margem do rio Paraguai por Justiniano, Souza e Pierangeli (2013) mostra que a presença do silte age como inibidora de coesão da argila, contribuindo para o recuo da margem. Segundo Resende (1985), a erosão tende a ser maior em solos com maiores teores de silte e areia e menor nos solos argilosos.

A segunda seção apresentou a seguinte distribuição da granulometria dos sedimentos de fundo: $35,60 \%$ de areia grossa, 17,64\% de areia média e a maior proporção foi de areia fina de $38,19 \%$, 7,91\% silte e $0,66 \%$ argila. No período chuvoso, reduziu o percentual de areia grossa, aumentou a proporção de areia média e areia fina. As frações de silte e argila tiveram seu percentual reduzido (Tabela 5).

Silva (2009) e Santos (2013), analisando a dinâmica fluvial de córregos de menor grandeza, encontraram valores pouco expressivos para os sedimentos mais finos, como silte e argila, nos primeiros quilômetros do alto curso. Esses resultados corroboram com o baixo percentual encontrado para o mesmo material no rio Carapá.

A análise da concentração dos sedimentos suspensos apontou $50 \mathrm{mg} / \mathrm{L}$ no período de estiagem, transportando carga de sedimentos suspensa de $0,378 \mathrm{t} / \mathrm{dia}$. No período chuvoso, a concentração dos sedimentos suspensos foi de $63 \mathrm{mg} / \mathrm{L}$ de material e carga suspensa 12,287 t/dia.

\section{Trecho 4}

Nesse trecho, a vegetação ciliar encontra-se parcialmente preservada, com espécies arbóreas de pequeno porte, arbustos, cipós e lianas lenhosas. O trecho possui padrão irregular, o barranco é íngreme na margem esquerda e rampeado na margem direita. Essa erosão diferenciada que acontece na margem esquerda está relacionada principalmente à composição granulométrica do sedimento.

Na terceira seção, no período de estiagem, o canal apresentou área molhada de $1,512 \mathrm{~m}^{2}$, a velocidade de fluxo da água era de $0,173 \mathrm{~m} / \mathrm{s}$ e vazão de $0,262 \mathrm{~m}^{3} / \mathrm{s}$. No período chuvoso, a área da seção molhada aumentou para $7,227 \mathrm{~m}^{2}$, a velocidade da água foi de $0,500 \mathrm{~m} / \mathrm{s}$ e a vazão do canal foi de $3,613 \mathrm{~m}^{3} / \mathrm{s}$ (Tabela 4).

$\mathrm{Na}$ seção 3, a análise granulométrica dos sedimentos de margem evidenciou o predomínio de areia, com 56,81\% de areia fina, seguida $39,93 \%$ de silte (tabela 14). O teor de agregados registrou que $43,53 \%$ dos sedimentos têm entre 2,00 a $4,00 \mathrm{~mm}$ seguido de $14,64 \%$ de sedimentos entre 1,00 a 2,00 $\mathrm{mm}$, revelando um médio grau de estabilidade dos agregados.

A erosão acumulada foi de $5 \mathrm{~cm}$ no pino mais próximo da lâmina de água e de $2 \mathrm{~cm}$ no pino próximo ao topo do barranco. A magnitude variou entre 0,19 a $0,47 \mathrm{~cm} / \mathrm{mês}$ (Tabela 2). A areia e o silte, principais componentes da margem, são materiais vulneráveis ao processo erosivo, por ser constituída por sedimentos finos, de fácil remoção e transporte.

Na margem esquerda (côncava), verifica-se processo erosivo intenso, deixando expostas raízes e troncos de árvores pelo solapamento basal. Na margem direita (convexa), ocorre a deposição de sedimentos no leito maior como areia, folhas e galhos (Figura 7).

Nessa seção, em relação ao material de fundo, predominam os sedimentos grosseiros (areia grossa, media e fina) nos dois períodos (estiagem e chuvoso). Os sedimentos mais finos de silte e de argila não ultrapassaram 4,19\% e $0,61 \%$, respectivamente, no período seco (Tabela 5).

O canal apresenta afloramento rochoso no fundo do leito e nas margens, que são erodidas pelo próprio rio, contribuindo para a carga detrítica do canal. Observou-se a presença de seixos e blocos rochosos no leito. Os fragmentos variam entre 30 a 230 mm de diâmetro.

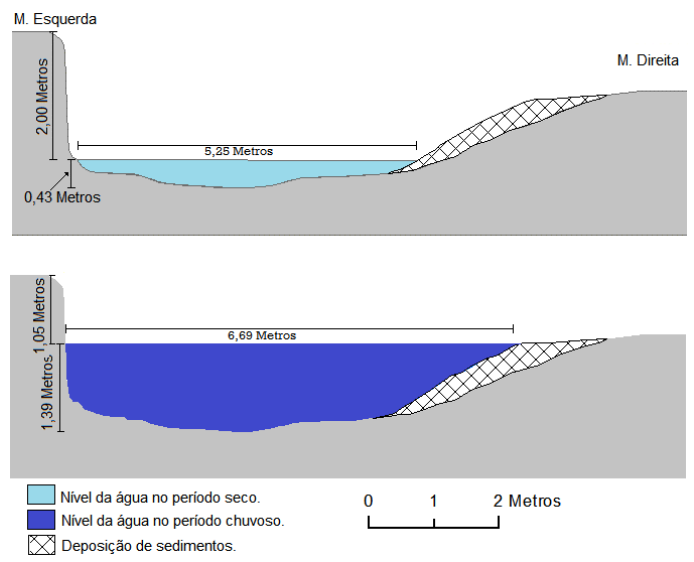

Figura 7 - perfil transversal seção 3, rio Carapá. 2016. Elaborado pelo autor. 


\section{Trecho 5}

No trecho 5, foram monitoradas duas seções (4 e 5), por tratar-se do local onde está localizada a estação de captação e tratamento de água potável para o município de Colíder. A seção 4 está a montante da barragem onde se encontra a bomba de captação. A área apresenta vegetação arbustiva, com poucas espécies arbóreas, pastagem e gramíneas. As margens praticamente não apresentam barranco, o que é resultado do represamento do canal, provocando alagamento do leito maior principalmente no período chuvoso.

A seção apresentou uma área de $9,426 \mathrm{~m}^{2}$ no período de estiagem e $16,239 \mathrm{~m}^{2}$ no período chuvoso (Figura 8), por tratar-se de um reservatório, com baixa velocidade do fluxo, não foram obtidos dados de vazão.

Na seção 4, predominou a concentração de silte, $55 \%$ no período estiagem e $39,25 \%$ no período chuvoso, seguido de $32,43 \%$ e $40 \%$ de areia fina. $\mathrm{Na}$ seção 5, predominou areia fina $66,16 \%$ (estiagem) e $77,09 \%$ (chuvoso). Essa diferença na proporção de concentração de silte pode ser explicada pelo fato da seção 4 ser uma barragem, onde a velocidade do fluxo é baixa, possibilitando a decantação dos materiais finos no fundo do canal.

Rocha e Souza Filho (2005, p. 31) concluíram que a interação entre a variação sazonal das condicionantes hidrodinâmicas e a entrada de material proveniente do rio Paraná, em seção transversal do canal Cortado, mostra-se insuficiente para o transporte contínuo de materiais entre areias médias e grossas encontradas no seu leito, permitindo a mobilização maior apenas de areias finas. Destacam ainda que tais variações são responsáveis pelo desenvolvimento de processos que concentram os sedimentos grosseiros.
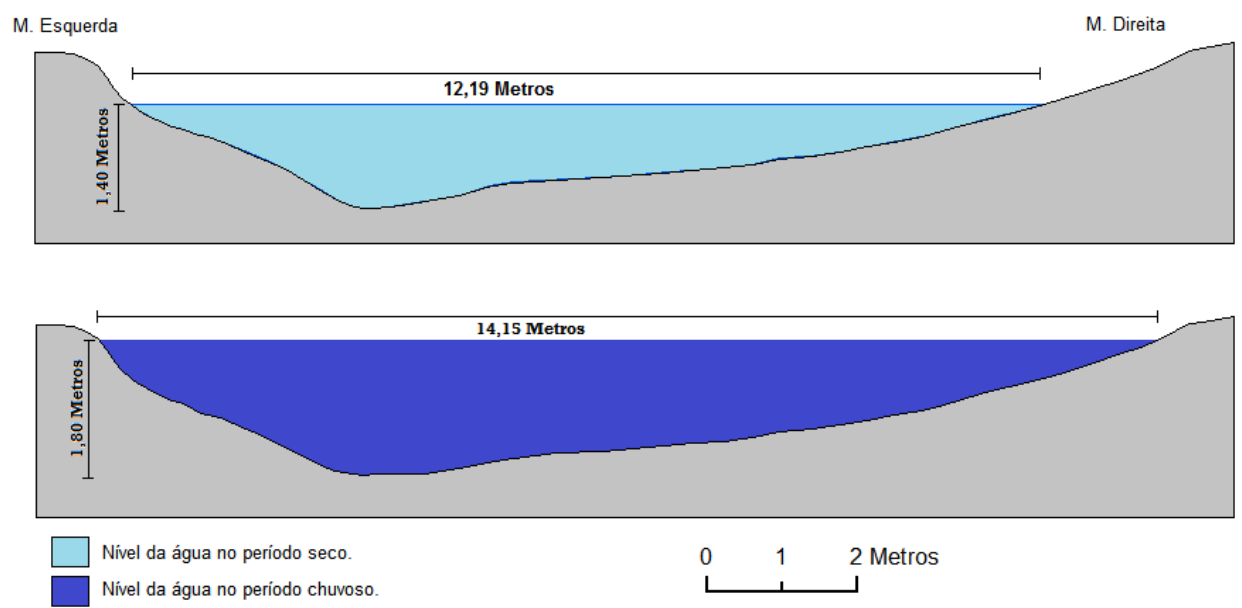

Figura 8 - Perfil transversal seção 4. Rio Carapá 2016. Elaborado pelo autor.

A quinta seção encontra-se no trecho retilíneo, com vegetação arbórea de pequeno porte em meio a várias espécies de cipós e trepadeiras. A área de APPs está resumida em apenas 2 a 5 metros na seção. Ao mesmo tempo, na jusante da seção monitorada, não há vegetação natural e a pastagem chega até a margem do canal, permitindo ao gado beber água diretamente no rio.

O canal é encaixado em formato de "U", com barranco escarpado nas duas margens (figura 9). A área da seção molhada no período estiagem era de $6,915 \mathrm{~m}^{2}$, a velocidade do fluxo era de $0,286 \mathrm{~m} / \mathrm{s}$ e a vazão de $0,235 \mathrm{~m}^{3} / \mathrm{s}$. No período chuvoso, a área da seção molhada aumentou para $14,778 \mathrm{~m}^{2}$, a velocidade do fluxo foi de $0,289 \mathrm{~m} / \mathrm{s}$ e a vazão foi de $4,282 \mathrm{~m}^{3} / \mathrm{s}$.

A seção 5 apresentou características arenosas, predominando a areia fina com $63,54 \%$ dos sedimentos analisados. Os sedimentos mais finos como silte e argila apresentaram 30,91 e 2,23\% respectivamente.

Para essa seção, os agregados apresentaramse pouco estáveis em água. As análises revelaram que apenas 20,91\% dos sedimentos com diâmetros entre 2,00 a $4,00 \mathrm{~mm}$ e $10,51 \%$ entre 1,00 a 2,00 $\mathrm{mm}$. De acordo com Pagliarini et al. (2012) e Souza et al. (2015), quanto maior o agregado, ou seja, quantos mais agregados forem retidos na maior classe de diâmetros, melhor é sua estabilidade e é mais difícil de haver a quebra no ponto de fraqueza.

A erosão acumulada ficou entre 2,8 a $3,1 \mathrm{~cm}$ e a magnitude de erosão variou entre 0,26 a 0,29 $\mathrm{cm} /$ mês. A alta taxa de erosão está relacionada à composição granulométrica dos sedimentos com predomínio de areia fina e silte com a baixa coesão 
das frações, facilmente removidos e transportados pela água.

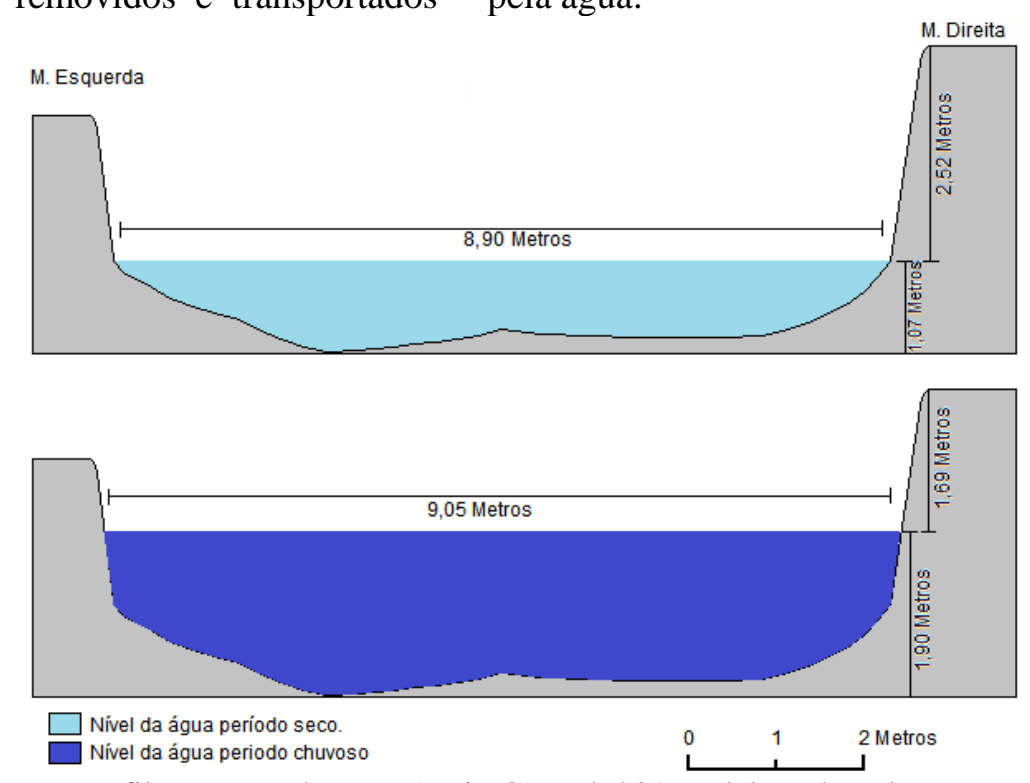

Figura 9 - Perfil transversal seção 5. Rio Carapá, 2016. Elaborado pelo autor.

De acordo com Christofoletti (1980), os sedimentos com granulometria reduzida (silte e argila) são tão pequenos e leves que se conservam em suspensão pelo fluxo turbulento da água, sendo transportados pela mesma velocidade em que a água flui. Se a velocidade do fluxo atinge o limite crítico, as partículas precipitam-se, iniciando o processo de deposição.

A concentração de sedimentos em suspensão na seção 4 foi de $39 \mathrm{mg} / \mathrm{L}$ no período seco e 252 $\mathrm{mg} / \mathrm{L}$ no período chuvoso. Na seção 5 , foi de 49 e $136 \mathrm{mg} / \mathrm{L}$, respectivamente. Na seção 5 , a vazão foi de $0,834 \mathrm{t} /$ dia no período estiagem e de 50,319 t/dia no período chuvoso.

A concentração de sedimentos suspensos pode variar de acordo com a velocidade do fluxo, ambiente fluvial e uso e ocupação do entorno. Nesse sentido, Leli et al. (2010, p. 51) afirmam que "a ocupação antrópica na bacia hidrográfica do rio Ivaí na sua mais ampla variedade tem alterado sensivelmente a concentração de sedimentos suspensos nos canais".

\section{Trecho 6}

No trecho 6 , foram monitoradas três seções por se tratar da confluência do rio Jaracatiá e o rio Carapá. O rio Jaracatiá é o principal afluente pela margem direita do rio Carapá, percorre vasta área, inclusive o perímetro urbano de Colíder. A sexta seção encontra-se no rio Jaracatiá; a sétima seção encontra-se no rio Carapá, a montante da confluência com o rio Jaracatiá, e a oitava seção encontra-se a jusante da mesma região.
No entorno da sexta seção, há pastagem e vegetação arbórea esparsa em processo de regeneração. O canal apresenta o leito com fundo parcialmente rochoso, com a presença de seixos de vários tamanhos.

A área da seção molhada no período de estiagem compreendia $0,157 \mathrm{~m}^{2}$, a velocidade do fluxo era de $0,331 \mathrm{~m} / \mathrm{s}$ e a vazão foi de $0,52 \mathrm{~m} / \mathrm{s}$. No período chuvoso, aumentou a área da seção molhada para $9,104 \mathrm{~m}^{2}$, velocidade do fluxo da água foi de $0,481 \mathrm{~m} / \mathrm{s}$ e vazão de $4,380 \mathrm{~m}^{3} / \mathrm{s}$. Essa seção registrou alagamento, preenchendo toda a margem plena no período de cheias (Figura 10).

Nessa seção a granulometria dos sedimentos de margem apresentou frações mais bem distribuídas; porém, predominou o silte, com $37,08 \%$, seguido de areia fina, representando $25,31 \%$. O mesmo aconteceu com o teor de agregados, que constatou uma diferença relativamente pequena na distribuição da porcentagem nas classes de tamanho dos agregados estáveis em água.

A erosão acumulada foi pequena, variando entre 0,4 e $0,6 \mathrm{~cm}$. A magnitude da erosão, que não ultrapassou $0,05 \mathrm{~cm} / \mathrm{mês}$, fez dessa seção a área que apresentou o menor índice de erosão de todos os trechos monitorados. O baixo potencial erosivo pode ser explicado pelo bom equilíbrio na granulometria dos sedimentos do barranco, também há a ocorrência de frações de argila que fornece maior estabilidade da margem.

A análise granulométrica dos sedimentos de fundo da sexta seção no rio Jaracatiá mostrou que o rio tem potencial de transportar sedimentos 
grosseiros. Foi constatado, nessa seção, que 41,06\% eram compostos de areia grossa e 30,19\% de areia média no período de estiagem. Já no período chuvoso, os números foram: $36,9 \%$ de areia grossa e $46,43 \%$ de areia média (Tabela 5).
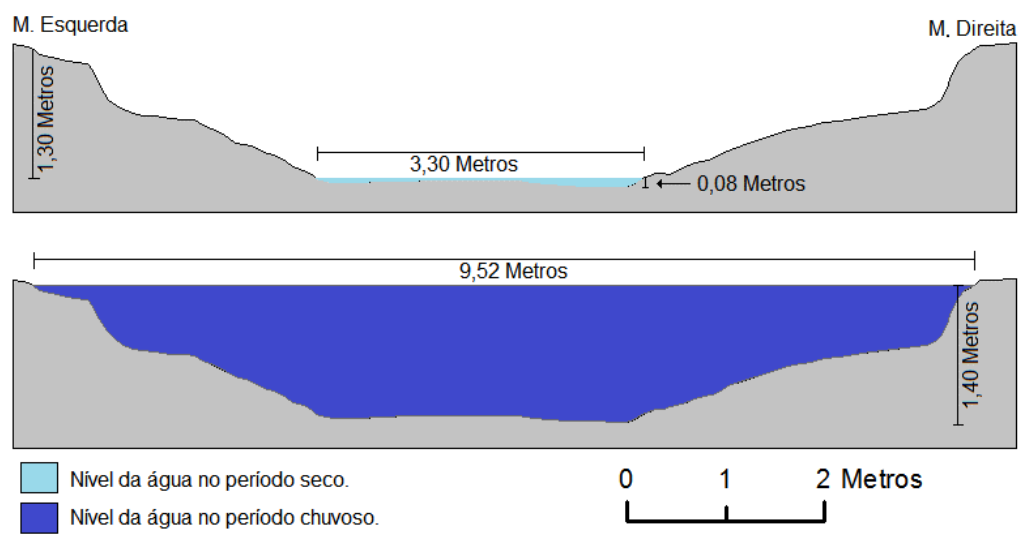

Figura 10 - Perfil transversal no rio Jaracatiá, Colíder, 2016. Elaborado pelo autor.

A sétima seção apresenta um canal encaixado em formato de "U", suas margens são escarpadas, com alto potencial erosivo (Figura 11). A vegetação arbórea ou arbustiva foi, na sua maioria, substituída por pastagem.

A batimetria revelou que a área molhada no período seco correspondia a $3,327 \mathrm{~m}^{2}$, a velocidade do fluxo de água era de $0,113 \mathrm{~m} / \mathrm{s}$ e vazão de 0,378 $\mathrm{m}^{3} / \mathrm{s}$. Enquanto, no período chuvoso, a área da seção molhada foi de $12,670 \mathrm{~m}^{2}$, a velocidade do fluxo de água era de $0,510 \mathrm{~m} / \mathrm{s}$ e vazão de $6,462 \mathrm{~m} 3 / \mathrm{s}$ (Tabela $4)$.

$\mathrm{Na}$ seção 7, predominaram os sedimentos mais finos, com destaque para o silte, que representou $61,44 \%$ das amostras analisadas. A areia grossa representou apenas $14,63 \%$ dos sedimentos. Com relação à estabilidade de agregados, o maior percentual de agregados estáveis em água foi de diâmetro entre 2,00 a 4,00, que representou $28,86 \%$ das amostras.

A predominância do silte e a presença de areia colaboraram para reduzir a estabilidade das margens, o que tornou essa margem susceptível à erosão marginal. A erosão acumulada para essa seção ficou entre 1,8 a $2,1 \mathrm{~cm}$ e a magnitude da erosão variou entre 0,2 a $0,14 \mathrm{~cm} /$ mês. Esses valores estão próximos à média de erosão das seções anteriores.
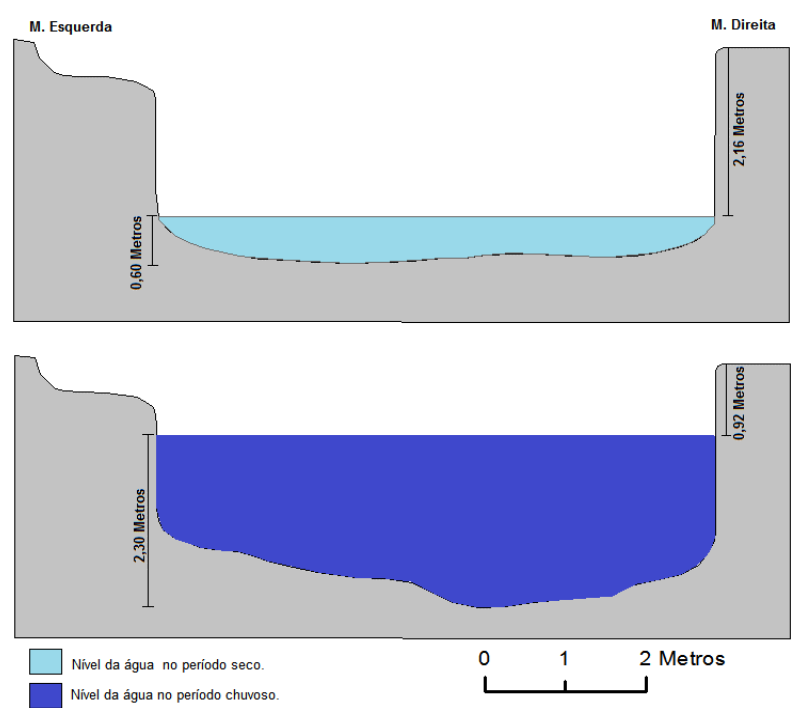

Figura 11 - Perfil transversal seção 7. Rio Carapá, Colíder, 2016. Elaborado pelo autor.

Na seção sétima, predominou a fração de areia fina no período estiagem: $61,96 \%$ da carga de sedimentos de fundo. No período chuvoso, os valores ficaram proporcionalmente distribuídos entre os sedimentos grosseiros (areia grossa, média e fina). 
A oitava seção encontra-se com canal retilíneo, as margens são rampeadas. A vegetação natural foi totalmente suprimida por pastagem. Com o intenso processo de sedimentação, que provocou a diminuição da profundidade do canal, aumentou a sua largura (Figura 12).
O canal apresenta afloramentos rochosos, principalmente na margem direita, e ocorrência de seixos e blocos de vários tamanhos. No centro, o canal possui um banco de sedimentos que é visível em todo o período de estiagem (Figura 12).
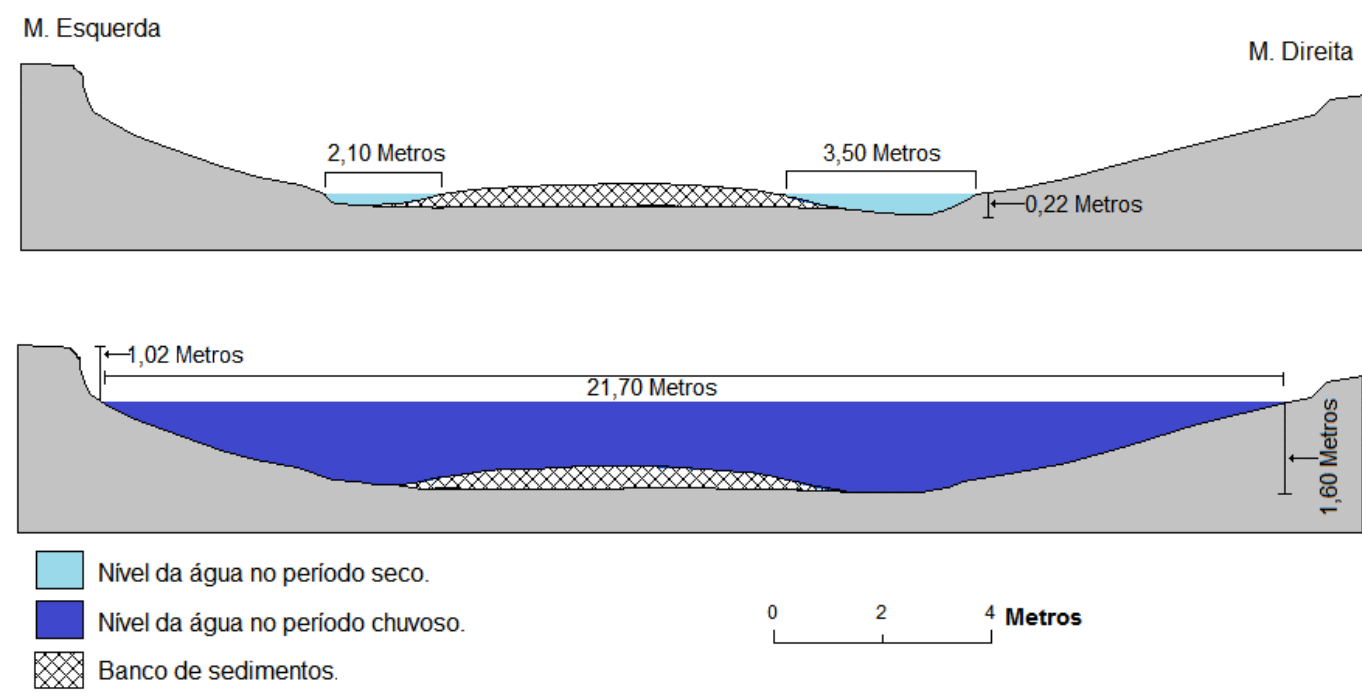

Figura 12 - Perfil Transversal seção 8. Rio Carapá, Colíder, 2016. Elaborado pelo autor.

A área da seção molhada no período de estiagem foi de $1,171 \mathrm{~m}^{2}$, a velocidade da água era de $0,398 \mathrm{~m} / \mathrm{s}$ e a vazão de $0,466 \mathrm{~m}^{3} / \mathrm{s}$. No período chuvoso, aumentou a área da seção molhada, atingindo $23,582 \mathrm{~m}^{2}$, a velocidade do fluxo da água foi de $0,472 \mathrm{~m} / \mathrm{s}$ e a vazão de $11,136 \mathrm{~m}^{3} / \mathrm{s}$. O aumento da vazão nessa seção está associado à contribuição do volume de água do rio Jaracatiá.

A oitava seção apresentou o maior percentual de areia grossa no período de estiagem $(75,74 \%)$. No período de chuvoso, predominaram as frações médias $(58,54 \%)$. A grande concentração de sedimentos grosseiros, possibilitou a formação de uma barra central de sedimentos no canal.

Nas seções 6, 7 e 8 , as concentrações de sólidos suspensos foram de $106 \mathrm{mg} / \mathrm{L}, 61 \mathrm{mg} / \mathrm{L}$ e 59 $\mathrm{mg} / \mathrm{L}$ no período de estiagem. No período chuvoso, as concentrações de sólidos suspensos foram: 78 $\mathrm{mg} / \mathrm{L}, 55 \mathrm{mg} / \mathrm{L}$ e $82 \mathrm{mg} / \mathrm{L}$. As três mostram a capacidade dos rios para transportar a carga suspensa, aumentando expressivamente no período chuvoso (Tabela 6).

\section{Trecho 7}

Nesse trecho, o canal possui o padrão meandrante, a margem côncava é íngreme e a margem convexa é rampeada (Figura 13). A vegetação natural foi retirada e substituída por pastagem, o gado tem acesso direto ao rio para dessedentação; a montante da seção existe uma ponte que contribuiu para modificar o leito. As alterações registradas no leito são os processos erosivos e sedimentação (barras).

$\mathrm{Na}$ seção nove, no período de estiagem, a área da seção molhada era de $7,262 \mathrm{~m}^{2}$, a velocidade do fluxo foi de 0,093 e a vazão foi de $0,680 \mathrm{~m}^{3} / \mathrm{s}$. No período chuvoso, a área da seção molhada foi de $36,746 \mathrm{~m}^{2}$, a velocidade foi de $0,750 \mathrm{~m} / \mathrm{s}$ e de 27,559 $\mathrm{m}^{3} / \mathrm{s}$.

Nesta seção, em relação à textura do material das margens, predominou o silte, sendo superior a 70\% (Tabela 1). As frações de areia grossa e fina não foram encontradas nas amostras e a fração argila representou $3,82 \%$.

$\mathrm{O}$ teor de estabilidade de agregados foi mais baixo $(3,27 \%)$ para os grãos maiores, entre $2,00 \mathrm{e}$ $4,00 \mathrm{~mm}$; e $6,08 \%$ entre 1,00 e $2,00 \mathrm{~mm}$. A maior concentração de agregados estáveis $(28,11 \%)$ foi registrada na classe de diâmetros entre 0,10 a 0,25 $\mathrm{mm}$. Esses resultados evidenciam que essa seção é a mais vulnerável à erosão. 

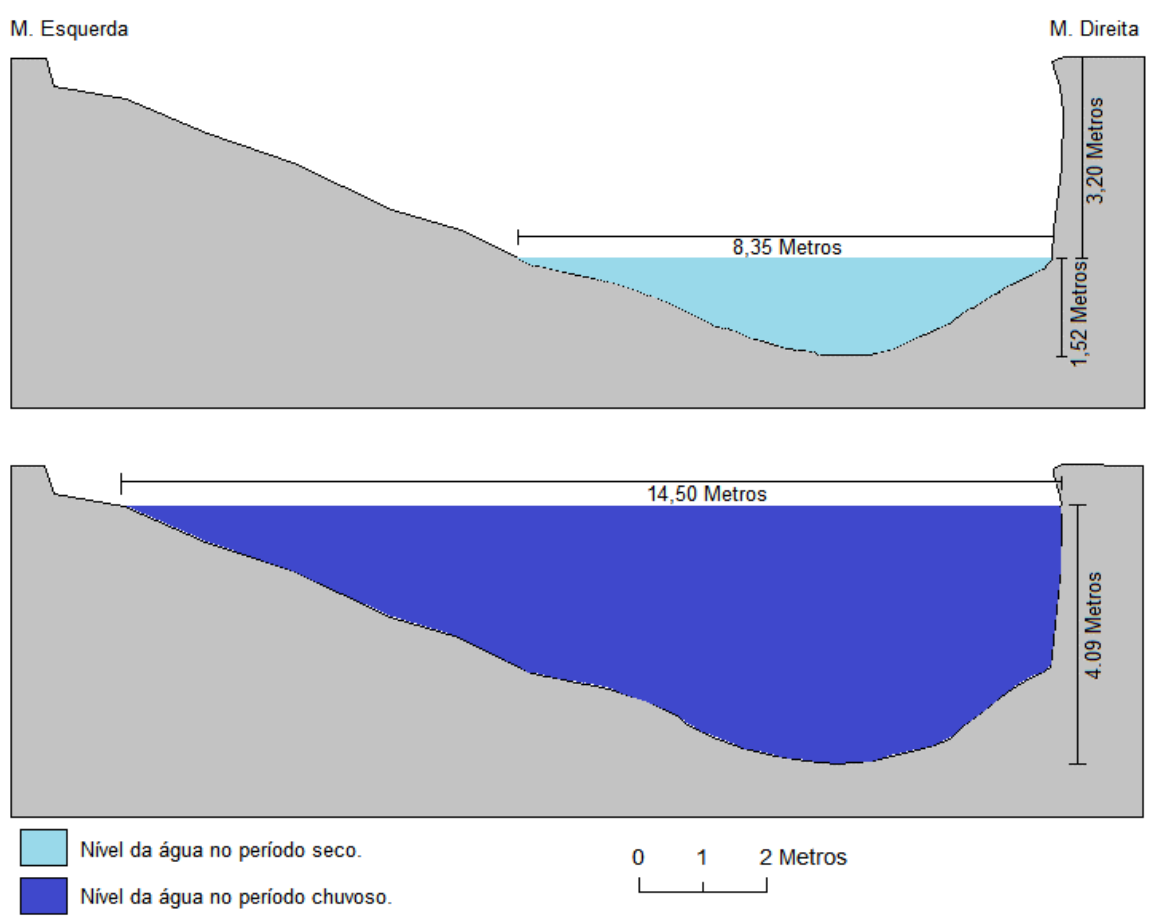

Figura 13 - Perfil Transversal seção 9. Rio Carapá, Colíder, 2016. Fonte: o autor.

Não foi possível obter as informações de erosão pela técnica de pinos, pois eles foram levados pelo próprio processo erosivo. Dessa forma, a erosão foi quantificada por meio da estaca fixada a 2,00 m da margem e, no dia da verificação, foi constatado uma distância de $1,70 \mathrm{~m}$, evidenciando uma erosão acumulada de $30,00 \mathrm{~cm}$.

$\mathrm{O}$ intenso processo erosivo ocorreu devido à grande concentração de silte no solo e ao baixo teor de agregados estáveis em água. Outro fator relevante deve-se ao fato de o local ser um meandro e o ponto de coleta estar na margem côncava, que naturalmente é a margem de erosão. As outras seções foram monitoradas em trechos retilíneos, apresentando menor índice de erosão.

Nessa seção, verificou-se a presença de várias barras de sedimentos com predominância de material grosseiro (seixos com tamanho que varia entre 5,0 a $08 \mathrm{~mm}$ e areia) no leito principal e no leito maior. Quanto às informações sobre a granulometria dos sedimentos de fundo, houve a predominância de areia fina no período de estiagem, com 44,03 \%; no período chuvoso ficou predominante a fração de areia média.

\section{Trecho 8}

O trecho de monitoramento da seção 10 ocorreu a 70 metros a montante da ponte de concreto da rodovia MT 320. Sua construção provocou mudanças no leito do rio e no seu entorno. Com exceção da área da rodovia, a vegetação natural está preservada com muitas espécies arbóreas de grande porte, cipós e lianas lenhosas. O canal está encaixado no relevo com margem rampeadas e escarpadas com fundo rochoso. $\mathrm{O}$ afloramento de rochas é visível no fundo e nas margens do rio.

A batimetria mostrou que a área da seção molhada no período de estiagem é de $4,229 \mathrm{~m}^{2}$, a velocidade do fluxo de $0,593 \mathrm{~m} / \mathrm{s}$ e vazão de 2,508 $\mathrm{m}^{3} / \mathrm{s}$. No período chuvoso, o nível da água subiu além dos limites da calha, transbordando sobre as duas margens provocando alagamento do leito maior (Figura 14). A área da seção no período chuvoso representava $43,611 \mathrm{~m}^{2}$, a velocidade do fluxo da água foi de $665 \mathrm{~m} / \mathrm{s}$ e vazão de $29,011 \mathrm{~m}^{3} / \mathrm{s}$.

A análise granulométrica do material da seção 10 mostrou o predomínio de silte $(56,35 \%)$; além disso, a fração argila $(5,13 \%)$ apresentou a maior concentração em todas as seções monitoras. As frações de areia grossa e média não alcançaram $9 \%$ na granulometria.

O solo da seção 10 apresentou a melhor estabilidade de agregados, concentrado $58,76 \%$ de agregados estáveis em água na classe de diâmetro entre 2,00 a 4,00 mm. Contribui para essa estabilidade o maior percentual de argila na composição do solo que ajudou a conter a erosão das margens.

Os valores de erosão acumulada ficaram entre 0,5 a $1,9 \mathrm{~cm}$ e a magnitude da erosão no período oscilou entre 0,04 a $0,18 \mathrm{~cm} / \mathrm{mês}$.

Na décima seção, houve predomínio de areia fina no fundo do canal, correspondendo $74,83 \%$ no 
período seco. No período chuvoso, os sedimentos grosseiros predominaram, porém apresentou 23,6\% de silte no material. Registrou-se também a presença de seixos com diâmetros entre 5,0 a $9,0 \mathrm{~mm}$.
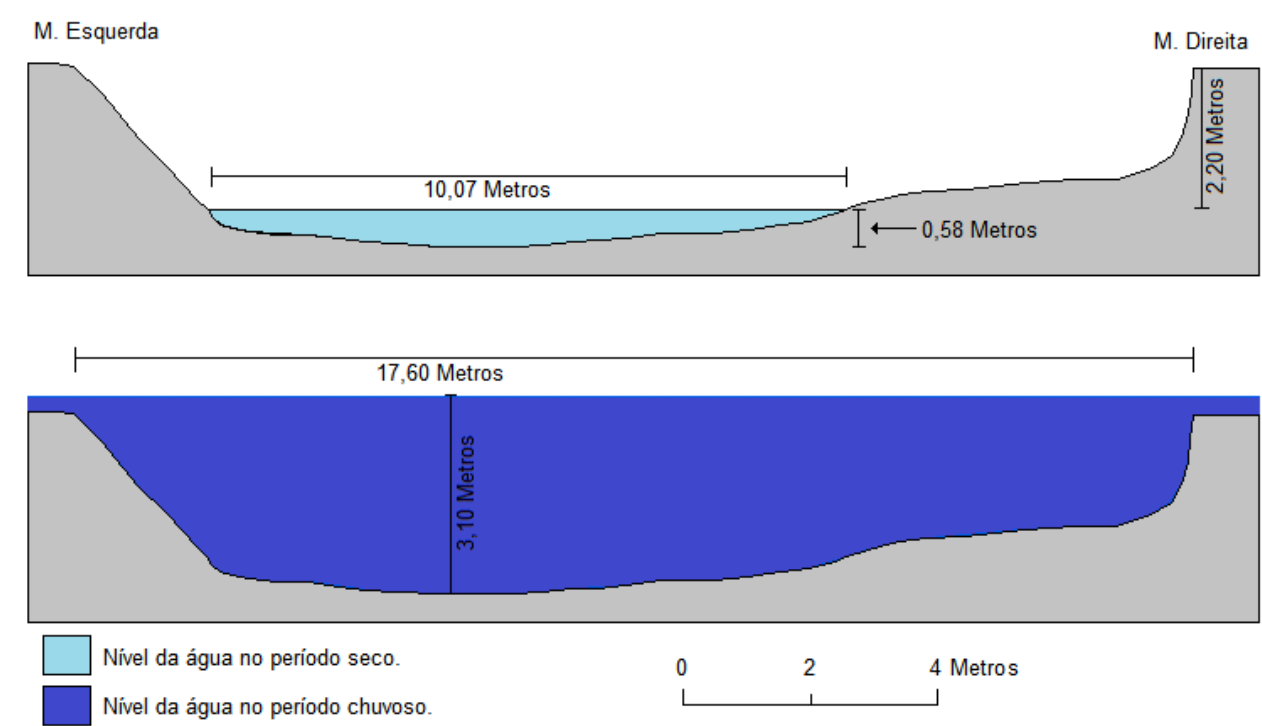

Figura 14 - Perfil transversal seção 10. Rio Carapá Colíder, 2016. Fonte: o autor.

A taxa de concentração de sedimentos em suspensão manteve-se entre $53 \mathrm{mg} / \mathrm{L}$ e $54 \mathrm{mg} / \mathrm{L}$ nos dois períodos; porém, a descarga sólida em suspensão foi de 11,486 t/dia no período estiagem, elevando-se para 135,355 t/dia no período de cheia.

\section{Trecho 9}

O trecho nove está a montante da confluência do rio Carapá com o rio do Meio que formam o rio Parado. Corresponde à área mais preservada de todos os trechos monitorados da bacia, com vegetação natural de médio e grande porte com várias espécies arbóreas como cedro (Cedrela fissilis), mogno (Swietenia macrophylla), canela (Cryptocarya aschersoniana), paineira (Chorisia speciosa), açaí (Euterpe olearacea Mart), ingazeiros de diversas espécies entre outros. Assim como em quase todos os pontos da pesquisa, existem também várias espécies de cipós, trepadeiras e lianas lenhosas, além de algumas espécies de vegetação arbustivas e plantas aquáticas.

A seção 11 apresenta um canal encaixado no relevo com margens escarpada, com alto potencial erosivo principalmente pela margem esquerda. Os troncos de árvores caídas ao longo do canal são resultados da erosão por solapamento basal que retira blocos de sedimentos abaixo das raízes levando à queda de árvores no leito do rio.

$\mathrm{Na}$ seção 11, a análise granulométrica dos sedimentos de margem, revelou maior percentual de areia fina $75,79 \%$. A fração silte registrou-se como $22,32 \%$ dos sedimentos, não sendo encontradas nessa seção as frações de areia grossa e média.
O teor de agregados estáveis em água ficou mais distribuído nas classes de diâmetros entre 0,10 a $0,25 \mathrm{~mm}, 0,25$ a $0,50 \mathrm{~mm}$ e 0,50 a $1,00 \mathrm{~mm}$. Esses valores, associados ao baixo percentual de argila $(1,89 \%)$, tornam solo muito suscetível a processos erosivos. Esses processos, por sua vez, ocorreram com muita intensidade, sendo registrada uma erosão acumulada entre 8,4 a $11 \mathrm{~cm}$. A magnitude de erosão registrada ficou entre 0,80 a $1,04 \mathrm{~cm} / \mathrm{mês}$. Foi a maior magnitude de erosão medida pela técnica de pinos na área de estudo.

A batimetria mostrou que a área da seção molhada do estudo possuía $11,591 \mathrm{~m}^{2}$ no período de estiagem, a velocidade do fluxo foi de $0,331 \mathrm{~m} / \mathrm{s}$ e a vazão de $3,838 \mathrm{~m} / \mathrm{s}$. No período chuvoso, a velocidade do fluxo foi de $0,728 \mathrm{~m} / \mathrm{s}$, a área da seção molhada era de $103,350 \mathrm{~m}^{2}$ e a vazão de $75,297 \mathrm{~m}^{3} / \mathrm{s}$ (Figura 15).

Nessa última seção, nos sedimentos de fundo, predominou a fração de areia fina, com 82,86 , e $84,09 \%$ nos dois períodos de monitoramento. A concentração de sedimentos em suspensão ficou em torno de $60 \mathrm{mg} / \mathrm{L}$ e a carga sólida suspensa foi de 19,899 t/dia no período de estiagem e de 396,850 t/dia no período chuvoso.

Com exceção da seção 11, todos os trechos monitorados sofreram alterações nas áreas de APPs foram suprimidas por pastagem (Figura 16). Essa prática que é comum em toda a área da bacia contribui para a erosão, assoreamento e diminuição do fluxo de água nos rios e córregos na área de estudo. 

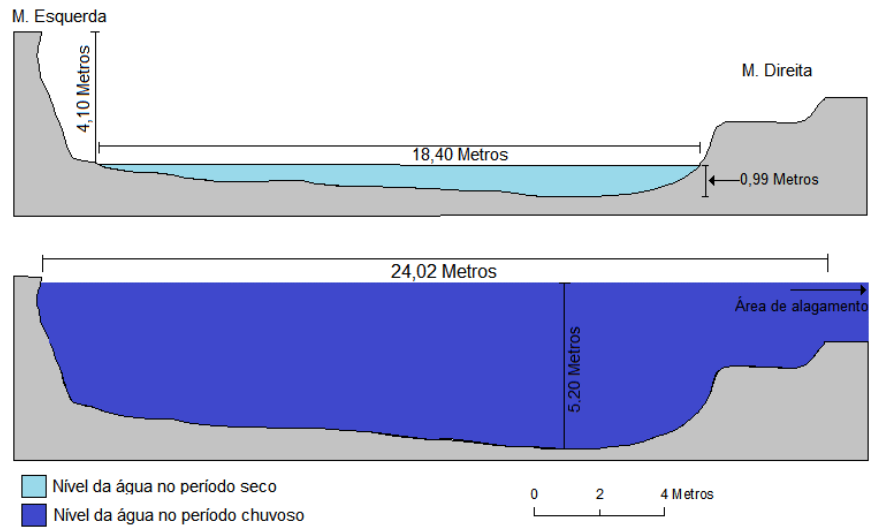

Figura 15 - Perfil transversal seção 11. Rio Carapá, Colíder e Nova Canaã do Norte, 2016. Fonte: o autor.

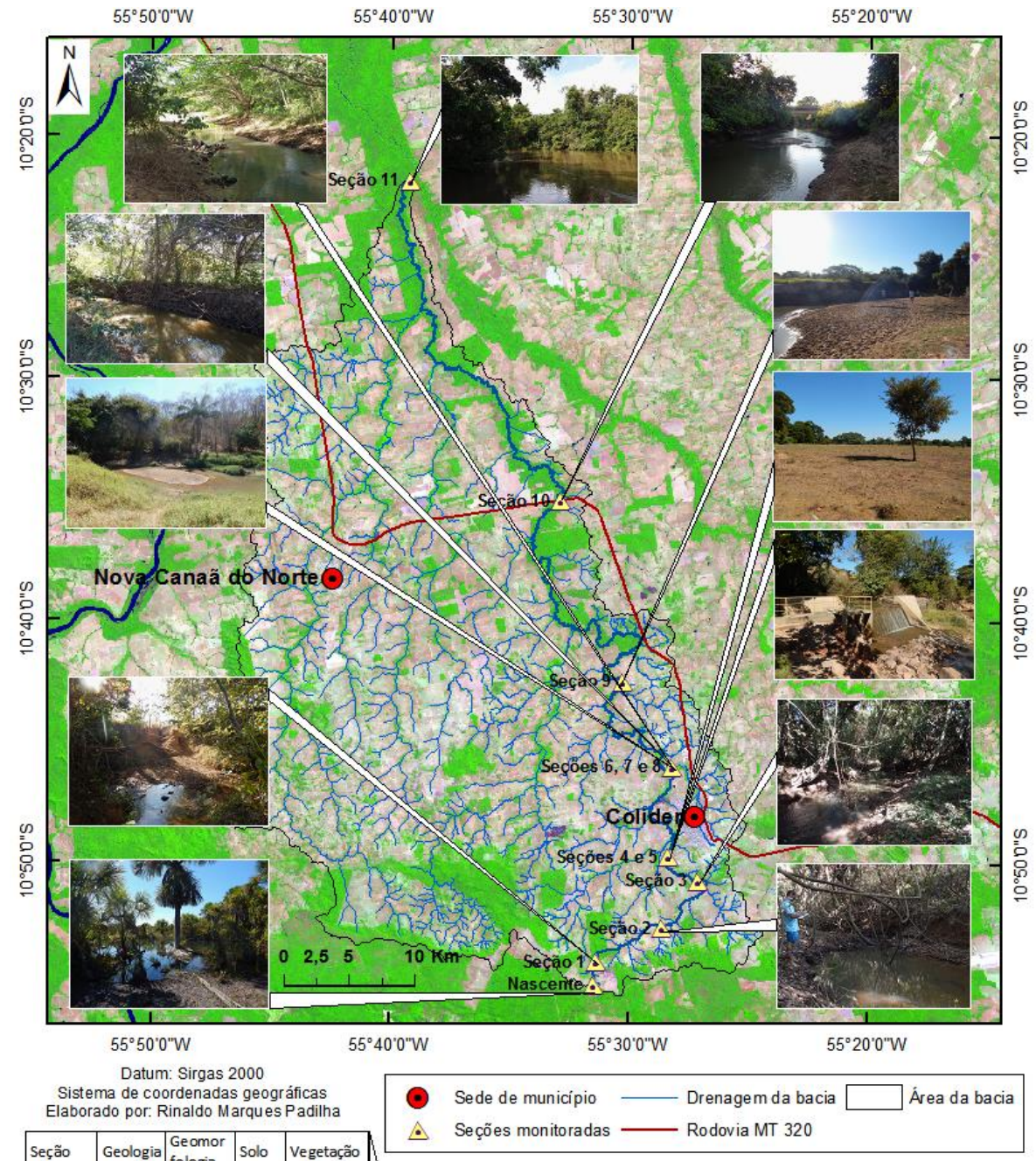

\begin{tabular}{|l|c|c|c|c|}
\hline Seção & Geologia & $\begin{array}{c}\text { Geomor } \\
\text { fologia }\end{array}$ & Solo & Vegetação \\
\hline Nascente & pEd & PPt & FFc & FDse \\
\hline 1 & pEia & DPc & NVd & FAsc \\
\hline 2 & pEia & DPc & FFc & FAsc \\
\hline 3 & pEia & DPc & NVd & FAsc \\
\hline 4 & pEia & DPc & NVd & FAsc \\
\hline 5 & pEia & DPc & NVd & FAsc \\
\hline 6 & pEia & DPc & PVAd & FAsc \\
\hline 7 & pEia & DPc & PVAd & FAsc \\
\hline 8 & pEia & DPc & PVAd & FAssc \\
\hline 9 & pEia & DPc & PVAd & FAsc \\
\hline 10 & pEx & DPc & PVAd & FAsc \\
\hline 11 & pEx & DPc & PVAd & FAsc \\
\hline
\end{tabular}

\begin{tabular}{|c|c|}
\hline \multirow{3}{*}{ Geologia } & pEd - Formação Dardanelos. \\
\hline & pEia - Formação Iriri. \\
\hline & pEx-Complexo Xingu. \\
\hline \multirow{2}{*}{$\begin{array}{l}\text { Geomor } \\
\text { fologia }\end{array}$} & PPt - Planalto dos Parecis - Formas tabulares. \\
\hline & DPc -Depressão Interplanáltica da Amazônia Meridional - Formas convexas. \\
\hline \multirow{3}{*}{ Solo } & FFC - Plintossolo Pétrico Concrecionário. \\
\hline & NVd - Nitossolo Vermelho Distrófico. \\
\hline & PVAd - Argissolo Vermelho-Amarelo Distrófico. \\
\hline \multirow{2}{*}{$\begin{array}{l}\text { Vegeta } \\
\text { ção }\end{array}$} & $\begin{array}{l}\text { FDse - Floresta Ombrófila Densa Tropical - Formação Submontana dossel } \\
\text { emergente. }\end{array}$ \\
\hline & FAsc - Floresta Omb rófila Aberta Tropical - Formação Submontana com cipó. \\
\hline
\end{tabular}

Figura 16 - Alterações e degradação ao longo do perfil longitudinal na bacia hidrográfica do rio Carapá, 2016. Fonte: o autor. 


\section{Considerações Finais}

A bacia hidrográfica do rio Carapá constitui uma importante rede de drenagem, que drena os municípios de Colíder e Nova Canaã do Norte, Mato Grosso. Sendo contribuinte da bacia do rio Teles Pires, estando inserida na bacia do rio Amazonas.

As informações sobre a dinâmica fluvial evidenciaram que o rio tem um alto potencial de transporte de sedimentos grosseiros, com predominância areia variando de areia grossa a fina nas seções. A concentração de sedimentos em suspensão variou entre 12 a $106 \mathrm{mg} / \mathrm{L}$ no período de estiagem e 16 a $252 \mathrm{mg} / \mathrm{L}$ no período chuvoso. Os maiores valores de descarga sólida suspensa foram registradas nas seções 10 e 11 no baixo curso, nos dois períodos (estiagem e chuvoso). A capacidade de transportar sedimentos foi maior no período chuvoso foi maior, a descarga sólida em suspensão chegou a 396,850 t/d na seção 11 . A vazão manteve a tendência natural de aumentar de montante para jusante e os maiores valores serem diagnosticados no período chuvoso. Variando de 0,047 a $3,838 \mathrm{~m}^{3} / \mathrm{s}$ no período de estiagem e 2,174 a 2,174 $\mathrm{m}^{3} / \mathrm{s}$ no período chuvoso.

A erosão acumulada nas margens pode estar associada alguns fatores: ao grau de curvatura das margens (raio hidráulico); altura do barranco; a proteção das margens (vegetação); a composição granulométrica (predominância de areia fina e silte em todas as seções) e a estabilidade dos agregados e; a velocidade do fluxo. Os maiores valores de erosão acumuladas foram obtidas na seção 11, no baixo curso.

\section{Agradecimentos}

A Secretaria de Estado de Educação de Mato Grosso, pelo apoio financeiro ao primeiro autor. Ao Programa de Pós-Graduação em Geografia da Universidade do Estado de Mato Grosso.

\section{Referências}

Almeida, J.C., Silva, V.N., Souza, C.A., Souza, I.C., 2014. Descrição Morfológica e Sedimentar do Rio Paraguai no Segmento entre o Poço do Renato a Baía da Inharosa. Revista Geonorte 4, 256-260.

Anstead, L., 2012. River bank erosion rates and the case for willow spiling as a bank stabilisation solution. Thesis (Doctor). Anglia, University of East Anglia.
Assine, M.L., Silva, A., 2009. Contrasting fluvial styles of the Paraguay River in the northwestern border of the Pantanal wetland, Brazil. Geomorphology 113, 189-199.

Balthazar, V., Vanacker, V., Girma, A., Poesen, J., Golla, S., 2012. Human impact on sediment fluxes within the Blue Nile and Atbara River basins. Geomorphology. [online]. Disponível: http://dx.doi.org/10.10 16/j.geomorph.2012.10.013. Acesso: 15 jan. 2017.

Bayer, M., Carvalho, T.M., 2008. Processos morfológicos e sedimentos no canal do Rio Araguaia. Revista de estudos ambientais 10 24-31.

Carvalho, N.O., Filizola Junior, N.P., Santos, P.M.C., Lima, J.E.F.W., 2000. Guia de práticas sedimentométricas. ANEEL, Brasília.

Carvalho, N.O., Filizola Junior, N.P., Santos, P.M.C., Lima, J.E.F.W., 2008. Hidrossedimentologia prática. 2. ed. Interciência, Rio de Janeiro.

Chaves, J.C.D., Calegari, A., 2001. Adubação verde e rotação de culturas. Informe Agropecuário 22, 53-60.

Chien, N., 1985. Changes in river regime after the construction of upstream reservoirs. Earth Surface Processes and Landscape 10, 143159.

Christofoletti, A., 1980. Geomorfologia. 2. ed. Edgard Blucher, São Paulo.

Christofoletti, A., 1981. Geomorfologia fluvial: o canal fluvial. 2 ed. Edgard Blücher, São Paulo.

Christofoletti, A., 1999. Modelagem de sistemas ambientais. Edgar Blücher, São Paulo.

Cunha. S.B., 1998. Bacias hidrográficas, in: Cunha, S.B., Guerra, A.J.T. (Org.), Geomorfologia do Brasil. Bertrand do Brasil, Rio de Janeiro, pp. 229-265.

Cunha. S.B., 2010. Geomorfologia fluvial, in: Cunha, S.B., Guerra, A.J.T. (Org.), Geomorfologia: exercícios, técnicas e aplicações. 4. ed. Bertrand do Brasil, Rio de Janeiro, pp. 157-189.

EMBRAPA. Empresa Brasileira de Pesquisa Agropecuária, 1997. Manual de métodos de análise de solo. Rio de Janeiro.

Fernandez, O.V.Q., 1990. Mudanças no canal fluvial do rio Paraná e processos de erosão nas margens: região de Porto Rico-PR. Dissertação (Mestrado). Rio Claro, UNESP.

Fernandez, O.V.Q., 1996. O método dos pinos na quantificação da erosão marginal em rios reservatórios, in: Simpósio Nacional de 
Geomorfologia. Anais. Uberlândia, Universidade Federal de Uberlândia, 160-163.

Grizio, E.V., Souza Filho, E.E., 2010. As modificações do regime de descarga do rio Paraguai Superior. Revista Brasileira de Geomorfologia 11, 25-33.

Humphries, M.S., Kindness, A., Elley, W.N., Hughes, J.C., Benitez-Nelson, C.R., 2010. $137 \mathrm{Cs}$ and $210 \mathrm{~Pb}$ derived sediment accumulation rates and their role in the longterm development of the Mkuze River floodplain, South Africa. Geomorphology 8896. Contents lists available at Science Direct Geomorphology, journal. [online]. homepage: <www.elsevier.com/locate/geomorph>.

Acesso: 13 jun. 2017.

Justiniano, L.A.A., Souza, C.A., 2010. Evolução das margens e transporte de sedimentos no rio Paraguai entre a foz do rio Sepotuba e a foz do rio Cabaçal, in: Santos, J.E., Galbiati, C., Moschini, L.E. (Org.), Gestão e Educação Ambiental: água, biodiversidade e cultura. Rima Editora, São Carlos, pp. 01-353.

Justiniano, L.A.A., Souza, C.A., Pierangeli, M.A.P., 2013. Migração lateral do rio Paraguai entre a foz do rio Sepotuba e a foz do rio Cabaçal em Mato Grosso. Revista GeoPantanal 8, 106-128.

Kuehn, E., 2015. Stream bank erosion trends and sediment contributions in a Southwestern Missouri river. Thesis (Doctor). Missouri State University.

Leandro, G.R.S., Souza, C.A., Chaves, I.J.F., 2012. Aspectos sedimentares na baía Negra, corredor fluvial do rio Paraguai, Pantanal de Cáceres (MT). Caminhos de Geografia, Uberlândia 13, 204-216.

Leandro, G.R.S., Souza, C.A., Nascimento, F.R., 2014. Processo de deposição fluvial na Baía Comprida, rio Paraguai, município de Cáceres, Mato Grosso, Brasil. Ra'eGa 31, 296-316.

Leli, I.T., Stevaux, J.C., Nóbrega, M.T., 2010. Produção e transporte da carga suspensa fluvial: teoria e método para rios de médio porte. Boletim de Geografia [online] 28 Disponível: http://dx.doi.org/10.4025/bolgeog r.v28i1.8472. Acesso: 10 jun. 2017.

IBGE. Instituto Brasileiro de Geografia e Estatística, 2009. Manual técnico de geomorfologia. Coordenação de Recursos Naturais e Estudos Ambientais. Rio de Janeiro.

Mobaraki, A.F., Ghodrati, A.R., Nazami, M.T., 2012. Investigation of Stabilization of River
Margins with use of Biological method for prevention of soil Erosion and sediment production. Intl J Agri Crop Sci 4, 691-695.

Oliveira, S., 1998. Colonização e massacre. Colíder.

Oliveira, V.S., 2006. Erosão marginal no baixo curso do rio São Francisco e seus efeitos nos agroecossistemas. Dissertação (Mestrado). São Cristóvão. UFS.

Orfeo, O., Stevaux, J., 2002. Hydraulic and morphological characteristics of middle and upper reaches of the Paraná River (Argentina and Brazil). Geomorphology 44, 309-322.

Pagliarini, M.K., Mendonça, V.Z., Alves M.C., 2012. Distribuição de tamanho de agregados estáveis em água em solos de Selvíria-MS e Ilha Solteira-SP, Brasil. Tecnologia \& Ciência Agropecuária 6, 45-51.

Peter, W.D., Andrew, S., 2001. Fluvial geomorphological analysis of the recruitment of large woody debris in the Yalobusha River network, Central Mississippi, USA. Geomorphology 37, 65-91.

Quinlan, E., Gibbins, C.N., Batalha, R.J., Verticat, D., 2014. Impacts of Small Scale Flow Regulation on Sediment Dynamics in an Ecologically Important pland River. Springer Science+Business Media New York 55, 671686.

Ramonell, C.G., Amsler, M.L., Orfeo, O., Montagnini, M.D., Perez, Melina., 2014. Ajustes morfológico-sedimentarios del río Bermejo en torno al Puente Lavalle (Chaco Argentino), Facultad de Ingeniería y Ciencias Hídricas, Universidad Nacional del Litoral 4575, 33-46.

Resende, M., 1985. Aplicação de conhecimentos pedológicos à conservação de solos. Informe Agropecuário 11, 3-18.

Rocha, P.C., Souza Filho, E.E., 2005. Interações dinâmicas entre os materiais do leito de um canal secundário com o canal principal no trecho multicanal do Alto Rio Paraná, Brasil. Revista Brasileira de Geomorfologia 6, 19-32.

Santos, M., 2013. Uso, ocupação da terra e dinâmica fluvial da bacia hidrográfica do córrego Cachoeirinha no município de Cáceres, Mato Grosso. Dissertação (Mestrado). Cáceres, UNEMAT.

Silva, E.S.F., Souza, C.A., Leandro, G.R.S., Galbiati., 2012. Evolução das feições morfológicas do rio Paraguai no Pantanal de Cáceres, Mato Grosso. Revista Brasileira de Geomorfologia 13, 435-442. 
Silva, E.S.F., 2012. Dinâmica fluvial do rio Paraguai no segmento entre o Furado do Touro e Passagem Velha, Pantanal de Cáceres, Mato Grosso. Dissertação (Mestrado). Cáceres, UNEMAT.

Silva, L.N.P., 2009. Bacia hidrográfica do córrego das Pitas, MT: dinâmica fluvial e o processo de ocupação, como proposta de gestão dos recursos hídricos. Dissertação (Mestrado). Cáceres, UNEMAT.

Sousa, J.B., Pierangeli, M.A., Souza, C.A., Cruz, J.S., Oliveira, J.D., 2017. Descrição morfológica e atributos do solo nas margens do rio Paraguai, Cáceres, Mato Grosso, Brasil. Ciência Geográfica XXI, 74-87.

Souza, C.A., 2004. Dinâmica do corredor fluvial do rio Paraguai entre a cidade de Cáceres e a Estação Ecológica da Ilha de Taiamã, MT. Tese (Doutorado). Rio de Janeiro, UFRJ.

Souza, C.A., Cunha, S.B., 2012. Feições morfológicas do rio Paraguai e sua dinâmica entre a cidade de Cáceres e a Estação Ecológica da Ilha de Taiamã, MT, in: SOUZA, C.A. (Org.), Bacia hidrográfica do rio Paraguai, MT: dinâmica das águas, uso, ocupação e degradação ambiental. Cubo, São Carlos, pp. 81-94.

Souza, C.A., Leandro, G.R.S, Sousa, J.B., Pierangeli, M.A., Ferreira, E., 2015. Informações preliminares sobre transporte de sedimentos no rio Paraguai entre a cidade de
Cáceres e a estação ecológica da ilha de Taiamã, Pantanal Superior, Mato Grosso, Brasil. Revista Portuguesa de Recursos Hídricos 36, 47-55.

Souza, C.A., Leandro, G.R.S., Sousa, J.B., Cunha, S.B., Garcia, P.H.M., 2017. Aporte de sedimentos dos afluentes da margem direita do rio Paraguai, Pantanal Superior - Mato Grosso - Brasil. Ciência Geográfica [online] XXI. Disponível:<http://www.agbbauru.org.b r/publicacoes/revista/anoXXI_1/agb_xxi_1_v ersao_internet/Revista_AGB_JanDez201702.pdf>. Acesso: 21 maio 2017.

Souza, L.H.C. Nunes, M.C.M., Neves, S.M.A.S., Cuiabano, M.N., Ferreira, F.S., Souza, A.L., 2015. Estabilidade de agregados de um Latossolo vermelho distrófico sob diferentes usos e manejos em Lambari D'Oeste-MT. Cerrado Agrociências 6, 12-23.

Suguio, K., 1973. Introdução à sedimentologia. Edgar Blücher, São Paulo.

Thorne, C.R., 1981. Field measurements of rates of bank erosion and bank material strength. Erosion and Sediment Transport Measurement Proceedings of the Florence Symposium. IAHS, 133.

Torres, F.T.P., Marques Neto, R., Menezes, S.O., 2012. Introdução à geomorfologia. Cengage Learning, São Paulo. 